\title{
ENRIQUECIMENTO ELEMENTAR POR MEIO DE CULTIVO: PLANTAS E COGUMELOS
}

\author{
Aline P. Oliveira ${ }^{a}$ e Juliana Naozuka*,a, (1) \\ ${ }^{a}$ Departamento de Química, Universidade Federal de São Paulo, 09972-270 Diadema - SP, Brasil
}

Recebido em 26/01/2020; aceito em 10/06/2020; publicado na web em 03/08/2020

\begin{abstract}
ELEMENTAL ENRICHMENT BY CULTIVATION: PLANTS AND MUSHROOMS. The foods enrichment with essential elements is an alternative to supply deficiencies of micronutrients and the fortification by rich cultivation is a promising strategy for the elemental enrichment of agricultural origin products, mainly in regions where there is high prevalence. On the other hand, in elemental enrichment procedures, possible antagonistic and / or synergistic relationships in the absorption and translocation of essential elements in agricultural products should be evaluated. Additionally, it is important to highlight the need to know the elements species capable of being absorbed and used in the metabolism of edible plants and mushrooms as well as the species formed after enrichment, being necessary to evaluate mainly if enriched foods present the same chemical characteristics, when compared to those grown under natural conditions. Therefore, in this review, works from the literature are presented involving promising strategies for elemental enrichment of edible plants and mushrooms grown in an appropriate medium, prioritizing the chemical characterization of the enriched food. Cultivation enrichment procedures are an excellent and promising alternative to help reduce elemental deficiencies as well as to maintain the recommended daily intake of these essential micronutrients for human nutrition and health.
\end{abstract}

Keywords: elemental enrichment; plants; mushrooms; chemical speciation; bioavailability.

\section{INTRODUÇÃO}

Uma alimentação ideal deve conter alimentos capazes de contribuir com todos os macro e micro nutrientes essenciais para a nutrição humana. A maioria dos alimentos comumente consumidos não apresenta concentrações capazes de suprir as necessidades de ingestão diária de diversos nutrientes essenciais, entre os quais podem-se destacar os microelementos. Portanto, projetos de educação alimentar, suplementos medicinais e fortificação/enriquecimento de alimentos têm sido recomendados para equilibrar e garantir uma alimentação saudável, assim como para elevar a qualidade de vida da população, reduzindo os índices de doenças e gastos com saúde pública. ${ }^{1}$

Os processos utilizados no enriquecimento alimentar consistem em adicionar aos alimentos um ou mais nutrientes, considerando o valor de ingestão dietética de referência (DRI) específico para cada componente adicionado à matriz alimentar, com o objetivo de reforçar o seu valor nutricional e prevenir ou corrigir eventuais deficiências nutricionais apresentadas pela população, favorecendo a manutenção ou recuperação da saúde e a prevenção de carências nutricionais. ${ }^{2} \mathrm{Um}$ alimento é considerado enriquecido ou fortificado se o enriquecimento ou fortificação de $100 \mathrm{~mL}$ ou $100 \mathrm{~g}$ do produto pronto para o consumo fornecer no mínimo $15 \%$ (alimentos líquidos) ou 30\% (alimentos sólidos) da DRI. ${ }^{3}$

O enriquecimento de alimentos já processados ou cultivados em meio rico é uma maneira de suprir a deficiência de micronutrientes, sendo uma alternativa de intervenção recomendada, principalmente para localidades onde se encontram elevadas prevalências. Em alimentos processados, a fortificação tem se mostrado um meio eficiente para reduzir os riscos de deficiências de micronutrientes na população. ${ }^{2}$ Os produtos lácteos e cereais são considerados as principais matrizes alimentares a serem fortificadas e apresentam diversas vantagens no que diz respeito a inclusão desses alimentos na dieta diária, uma vez que são largamente consumidos e bem estabelecidos como componentes nutricionais em dietas infantis. No entanto, é muito importante a seleção correta do composto e do

*e-mail: j.naozuka@unifesp.br alimento usado como veículo de transporte. Estudos indicaram que a biodisponibilidade relativa do ferro $(\mathrm{Fe})$ utilizado no enriquecimento pode variar de 5 a $100 \%$, dependendo da fonte de Fe utilizada. ${ }^{4}$ Os principais compostos usados para a fortificação de alimentos são sulfato ferroso (100\% biodisponível ao homem), furamato ferroso e succinato ferroso (90-100\% biodisponível ao homem) e pirofosfato férrico (20-70\% biodisponível ao homem), os quais são adicionados aos alimentos já processados e pronto para o consumo, tais como farinha de trigo e farinha de milho, pois apresentam baixa reatividade química, não alteram as caraterísticas organolépticas dos alimentos e possuem diferentes biodisponibilidades. ${ }^{2,5-7}$

O cultivo de alimentos de origem agrícola, tais como arroz, brotos comestíveis, cogumelos, feijão, frutas e nozes, em solos enriquecidos ou meios de cultivo previamente tratados com os micronutrientes de interesse também é um método promissor de enriquecimento alimentar e adição de microelementos essenciais à saúde humana. Dentre as estratégias mais eficazes para promover o aumento nas concentrações de elementos essenciais em produtos agrícolas encontram-se a fortificação do meio de cultivo (solos ou substratos) com a adição de sais do elemento, tratamento foliar através da pulverização da planta com solução contendo o elemento, imersão das sementes em solução enriquecida antes do plantio e o cultivo hidropônico da semente em solução nutritiva enriquecida. ${ }^{89}$

Nesse contexto, o cultivo de produtos agrícolas capazes de bioacumular elementos essenciais aliado a procedimentos de enriquecimento alimentar pode ser uma excelente alternativa para suprir deficiências nutricionais que dizem respeito a elementos específicos em conjunto com componentes que contribuem para a disseminação de uma alimentação saudável e funcional. ${ }^{10}$ É importante destacar também as estratégias de enriquecimento múltiplo, as quais são mais viáveis economicamente quando comparadas ao procedimento que visa o aumento nos níveis de apenas um nutriente nos alimentos, além de serem aplicados com sucesso para elevar a qualidade de vida, principalmente das populações em países em desenvolvimento. Por outro lado, apesar dos métodos de adição múltipla de elementos essenciais ao solo ou substrato de cultivo serem promissores e largamente utilizados na produção de produtos agrícolas enriquecidos, 
a translocação de alguns micronutrientes das raízes para as partes comestíveis das plantas através do xilema ainda é um desafio para a aplicação de estratégias de enriquecimento múltiplo bem sucedidas, uma vez que podem ocorrer interações que alteram a absorção de um elemento na presença de outro elemento, assim como alterações no metabolismo da planta que modificam significativamente a taxa de translocação elementar. ${ }^{11}$

Devido aos diferentes mecanismos de absorção e biodisponibilidade de cada elemento para as plantas e fungos, é fundamental destacar que é preciso conhecer as espécies elementares capazes de serem absorvidas, bem como as espécies formadas após o enriquecimento, sendo necessário avaliar se esses alimentos fortificados apresentam as mesmas características químicas daquelas formadas quando o alimento é cultivado em condições naturais. Adicionalmente, estudos de competição entre elementos devem ser levados em consideração quando se visa o enriquecimento com vários elementos simultaneamente. ${ }^{10,12}$

Assim sendo, para o sucesso do enriquecimento, estudos de especiação química elementar são de suma importância, pois permitem identificar e/ou determinar as formas químicas em que o elemento é encontrado em determinada matriz. ${ }^{13} \mathrm{~A}$ determinação das diferentes formas químicas dos elementos pode resultar em informações sobre a absorção dos elementos e subsequentemente a sua utilização para realização das funções fisiológicas, ou seja, a especiação química pode estimar a biodisponibilidade do nutriente. ${ }^{14}$

A biodisponibilidade de um elemento é definida como a fração ingerida do mineral que é absorvida e, posteriormente, usada para as funções fisiológicas. ${ }^{15}$ Estudos de biodisponibilidade podem ser realizados in vivo, utilizando seres humanos ou animais, ou através da realização de testes in vitro. ${ }^{16}$ No caso de ensaio in vitro faz-se estudos de bioacessibilidade. Os estudos in vivo são mais caros e muitas vezes limitados por questões éticas. ${ }^{17}$ Como uma alternativa, métodos in vitro têm sido propostos a fim de avaliar as frações bioacessíveis dos compostos nos alimentos. ${ }^{16}$ Os métodos in vitro quantificam a capacidade solúvel ou dialisável do nutriente, mas não a biodisponibilidade propriamente dita, uma vez que nem todo material solúvel ou dialisável é absorvido. ${ }^{14}$ No entanto, são fundamentais para auxiliar testes in vivo, uma vez que, nesses ensaios utiliza-se um grande número de cobaias que estão sujeitos a diversos fatores externos e genéticos. ${ }^{14,15}$

Estudos de especiação química e bioacessibilidade promovem conhecimentos capazes de auxiliar na evolução e aprimoramento de informações a respeito da utilização consciente de alimentos funcionais, uma vez que, esses consistem em uma fonte que além de apresentar suas funções nutricionais como fonte de energia e de substrato para a formação de células e tecidos, possuem também em sua composição, uma ou mais espécies químicas capazes de agir no sentido de modular os processos metabólicos das pessoas prevenindo o aparecimento precoce de doenças degenerativas, levando ao aumento da longevidade. ${ }^{18}$

Diante do exposto, é crescente o interesse da comunidade científica no desenvolvimento de estratégias de enriquecimento de alimentos e de acordo com a base de dados Web of Science, entre os anos de 2000 e 2019 e considerando a palavra chave "food enrichment", houve um aumento significativo no número de publicações científicas, Figura $1 .{ }^{19}$ Considerando essas publicações, é notável o interesse em estratégias de fortificação elementar de vários alimentos, de acordo com a Tabela 1.

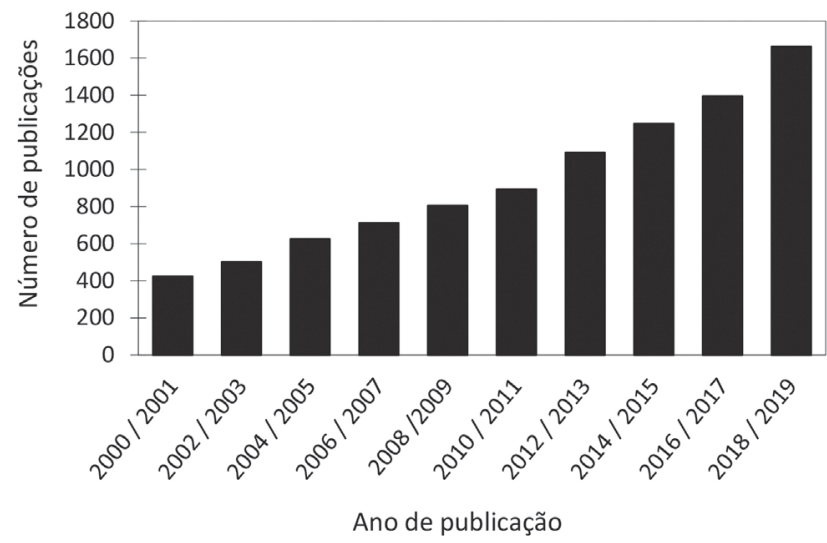

Figura 1. Relação aproximada do número de publicações científicas envolvendo enriquecimento de alimentos entre os anos de 2000 e 2019

Tabela 1. Alimentos submetidos ao enriquecimento elementar por meio de cultivo

\begin{tabular}{|c|c|c|c|}
\hline \multicolumn{4}{|c|}{ ENRIQUECIMENTO DE ALIMENTOS } \\
\hline Alimentos & Elementos essenciais & Estratégias de enriquecimento & Referência \\
\hline Alface & Manganês, Selênio e Zinco & $\begin{array}{l}\text { Suplementação de solução nutritiva em cultivo hidropônico, solo e } \\
\text { cultivo de mudas em substrato suplementado }\end{array}$ & {$[20-28]$} \\
\hline Alho & Selênio & $\begin{array}{l}\text { Suplementação do solo de cultivo, imersão dos dentes de alho em } \\
\text { solução fortificada, pulverização da planta e suplementação de solução } \\
\text { nutritiva em cultivo hidropônico }\end{array}$ & {$[29-32]$} \\
\hline Arroz & Ferro & Imersão de sementes em solução fortificada & {$[33]$} \\
\hline Batata & Selênio & Suplementação de solução nutritiva em cultivo hidropônico & [34] \\
\hline$\underline{B} \underline{B}$ rotos de alfafa & Ferro e Magnésio & Suplementação do meio de cultivo & {$[35,36]$} \\
\hline Brotos de alho & Selênio & Suplementação de solução nutritiva em cultivo hidropônico & {$[37]$} \\
\hline Brotos de brócolis & Ferro, Magnésio e Selênio & $\begin{array}{l}\text { Suplementação do meio de cultivo, pulverização foliar e imersão das } \\
\text { sementes em solução fortificada }\end{array}$ & {$[35,36,38-41]$} \\
\hline Brotos de cebola & Selênio & Imersão das sementes em solução fortificada & [39] \\
\hline Brotos de couve & Selênio & Suplementação do meio de cultivo & {$[41]$} \\
\hline Brotos de ervilha & Selênio e Zinco & Imersão das sementes em solução fortificada e pulverização da planta & {$[42,43]$} \\
\hline Brotos de feijão azuki & Ferro e Selênio & Suplementação do meio de cultivo & {$[11,44,45]$} \\
\hline Brotos de feijão mungo & $\begin{array}{l}\text { Cobre, Cobalto, Ferro, Magnésio, } \\
\text { Manganês, Selênio e Zinco }\end{array}$ & $\begin{array}{l}\text { Suplementação do meio de cultivo ou imersão das sementes em solução } \\
\text { enriquecida }\end{array}$ & {$[35,36,39,46-48]$} \\
\hline Brotos de mostarda & Selênio & Pulverização das sementes com solução fortificada & {$[40]$} \\
\hline Brotos de rabanete & Ferro, Magnésio e Selênio & $\begin{array}{l}\text { Suplementação do meio de cultivo e imersão das sementes em solução } \\
\text { fortificada }\end{array}$ & {$[35,36,49]$} \\
\hline Brotos de repolho & Selênio & Pulverização das sementes com solução fortificada & [40] \\
\hline
\end{tabular}


Tabela 1. Alimentos submetidos ao enriquecimento elementar por meio de cultivo (cont.)

\begin{tabular}{|c|c|c|c|}
\hline \multicolumn{4}{|c|}{ ENRIQUECIMENTO DE ALIMENTOS } \\
\hline Alimentos & Elementos essenciais & Estratégias de enriquecimento & Referência \\
\hline Brotos de soja & Ferro e Selênio & Imersão das sementes em solução fortificada & {$[48,50]$} \\
\hline Brotos de trigo & Selênio & Suplementação do meio de cultivo & [43] \\
\hline Cebola & Cobre, Selênio e Zinco & Suplementação de solução nutritiva em cultivo hidropônico & {$[51,52]$} \\
\hline Cenoura & Selênio & Pulverização foliar & [53] \\
\hline Couve & Selênio & Suplementação de solução nutritiva em cultivo hidropônico & [54] \\
\hline Folhas de agrião & $\begin{array}{l}\text { Cobre, Cobalto, Ferro, Manganês e } \\
\text { Zinco }\end{array}$ & Imersão das sementes em solução enriquecida & [46] \\
\hline Folhas de chá verde & Selênio & Pulverização foliar & [8] \\
\hline Grãos de ervilha & Zinco e Selênio & Pulverização foliar & [55] \\
\hline Grãos de feijão & Selênio & Pulverização foliar ou imersão das sementes em solução fortificada & {$[53,56]$} \\
\hline Grãos de lentilha & $\begin{array}{l}\text { Cobalto, Cobre, Ferro, Manganês, } \\
\text { Selênio e Zinco }\end{array}$ & $\begin{array}{l}\text { Suplementação do solo de cultivo, pulverização foliar ou imersão das } \\
\text { sementes em solução fortificada }\end{array}$ & {$[13,46]$} \\
\hline Grãos de milho & Selênio & Suplementação do solo de cultivo & [57] \\
\hline Grãos de soja & $\begin{array}{l}\text { Ferro, Cobre, Selênio, Zinco, Cobalto } \\
\text { e Manganês }\end{array}$ & $\begin{array}{l}\text { Imersão das sementes em solução fortificada ou suplementação do } \\
\text { solo de cultivo }\end{array}$ & {$[46,58,59]$} \\
\hline Nabo & Selênio & Suplementação do solo de cultivo & [60] \\
\hline Opuntia & Selênio & Suplementação do meio de cultivo & [61] \\
\hline Pepino & Selênio & Cultivo de mudas em substrato enriquecido & [25] \\
\hline Tomate & Selênio & $\begin{array}{l}\text { Suplementação de solução nutritiva em cultivo hidropônico ou cultivo } \\
\text { de mudas em substrato suplementado }\end{array}$ & {$[25,62]$} \\
\hline Trigo & Selênio & Suplementação de solução nutritiva em cultivo hidropônico & {$[1,11]$} \\
\hline \multicolumn{4}{|c|}{ ENRIQUECIMENTO DE COGUMELOS COMESTÍVEIS } \\
\hline Agaricus bisporus & Cobre, Selênio e Zinco & Suplementação do substrato de cultivo & [63-68] \\
\hline Agaricus blazei Murrill & Cobre e Zinco & Suplementação do substrato de cultivo & [69] \\
\hline Calocybe indica & Selênio & Suplementação do substrato de cultivo & [70] \\
\hline Cordyceps militaris & Selênio & Suplementação do substrato de cultivo & [71] \\
\hline Flammulina velutipes & Selênio & Suplementação do substrato de cultivo & [72] \\
\hline Ganoderma lucidum & Cobre, Selênio e Zinco & Suplementação do substrato de cultivo & [73-75] \\
\hline Grifola frondosa & Cobre, Selênio e Zinco & Suplementação do substrato de cultivo & {$[76,77]$} \\
\hline Lentinula edodes & Cálcio e Selênio & Suplementação do substrato de cultivo & [78-81] \\
\hline $\begin{array}{l}\text { Pleurotus citrinopilea- } \\
\text { tus }\end{array}$ & Selênio & Suplementação do substrato de cultivo & [66] \\
\hline Pleurotus cornucopiae & Ferro e Selênio & Suplementação do substrato de cultivo & {$[76,82,83]$} \\
\hline Pleurotus djamor & Ferro e Selênio & Suplementação do substrato de cultivo & {$[11,82-86]$} \\
\hline Pleurotus eryngii & Selênio & Suplementação do substrato de cultivo & {$[85,86]$} \\
\hline Pleurotus florida & Selênio & Suplementação do substrato de cultivo & [87] \\
\hline Pleurotus nameko & Selênio & Suplementação do substrato de cultivo & [85] \\
\hline Pleurotus ostreatus & Cálcio, Ferro, Lítio, Selênio e Zinco & Suplementação do substrato de cultivo & $\begin{array}{c}{[9,11,66,79,} \\
82-86,88-97,98,99]\end{array}$ \\
\hline Pleurotus pulmonarius & Selênio e Ferro & Suplementação do substrato de cultivo & {$[82,83]$} \\
\hline Pleurotus sajor-caju, & Selênio & Suplementação do substrato de cultivo & {$[66,98]$} \\
\hline Volvariella volvacea & Selênio & Suplementação do substrato de cultivo & {$[96,98]$} \\
\hline
\end{tabular}

Dessa forma, essa revisão visa fazer uma discussão de artigos da literatura envolvendo estratégias promissoras de enriquecimento elementar de plantas e cogumelos comestíveis que foram cultivados em meio fortificado com elementos essenciais, conforme destacados na Tabela 1. Uma maior ênfase será dada às estratégias de enriquecimento com Fe e Se aplicadas para brotos de feijão azuki (Vigna angularis) e ao enriquecimento com Se para shimeji branco (Pleurotus ostreatus) e cogumelo salmão ou "hiratake salmon" (Pleurotus djamor).

\section{Plantas comestíveis enriquecidas por meio de cultivo}

A adição de elementos essenciais à saúde humana por meio de adubação no solo agrícola é considerada uma estratégia promissora para o enriquecimento de plantas. O Centro Internacional de
Agricultura Tropical (CIAT) e o Instituto Internacional de Pesquisa em Políticas Alimentares (IFPRI, do inglês International Food Policy Research Institute) coordenam o programa Harvest Plus, que é parte do Programa de Pesquisa na Agricultura para Nutrição e Saúde (A4HN, do inglês Agriculture for Nutrition and Health) e do Grupo Consultivo sobre Pesquisa Agrícola Internacional (CGIAR, do inglês Consultative Group on International Agricultural Research), sendo uma aliança global entre instituições de pesquisa e entidades executoras que se uniram para melhorar e disseminar produtos, melhorando suas qualidades nutricionais por meio da biofortificação. Os estudos foram iniciados para seis produtos agrícolas de primeira necessidade: feijão, mandioca, milho, arroz, batata doce e trigo, os quais são largamente consumidos mundialmente sendo importantes nas dietas das populações, inclusive das pessoas que sofrem de deficiência de 
micronutrientes. A fase inicial do programa teve como objetivo gerar tecnologias e conhecimentos para o desenvolvimento de cultivos desses alimentos com melhor qualidade proteica e maiores teores de $\mathrm{Fe}, \mathrm{Zn}$ e vitaminas, visando o plantio e consumo em diversos países em desenvolvimento. ${ }^{100}$

Um estudo realizado no Instituto Agronômico de Campinas teve como objetivo aumentar o teor de Se em feijões cultivados em solo fortificado com Se(VI), aplicando $5000 \mathrm{~g} \mathrm{ha}^{-1}$ desse elemento. Os resultados indicaram que houve translocação do Se presente no solo de cultivo para os grãos de feijão produzidos, após o desenvolvimento do feijoeiro. ${ }^{101}$ Smrkolj et al. ${ }^{56}$ avaliaram duas formas diferentes de enriquecimento de feijoeiro com Se, tendo o $\mathrm{Se}(\mathrm{VI})$ como fonte elementar, que consistiu no cultivo em solo e pulverização foliar em um intervalo de 10 dias com solução de $10 \mathrm{mg} \mathrm{L}^{-1}$ no tempo de floração e uma segunda estratégia de enriquecimento, as plantas foram cultivadas hidroponicamente e as sementes foram previamente imersas em solução contendo Se. A estratégia de pulverização foliar mostrou-se mais eficaz para o acúmulo de Se nos grãos de feijão produzidos e, após a hidrólise enzimática, a porcentagem de Se solúvel também mostrou-se maior para essa estratégia de enriquecimento. ${ }^{56}$

Em estudos envolvendo a produção de grãos de feijão ricos em Se foram avaliadas diferentes estratégias de enriquecimento: pulverização das folhas com solução contendo $10 \mathrm{mg} \mathrm{L}^{-1}$ de $\mathrm{Se}(\mathrm{VI})$ ou imersão das sementes em solução com mesma concentração de $\mathrm{Se}(\mathrm{VI})$, sendo as plantas cultivadas hidroponicamente. Não foram verificadas diferenças significativas entre as diferentes estratégias de cultivo no que diz respeito as espécies de Se encontradas nos grãos de feijão produzidos, no qual selenometionina (SeMet) e seleno-metil-selenocisteína (SeMeSeCys) foram as espécies predominantes após procedimentos de hidrólise enzimática. ${ }^{53,59}$

O consumo de alimentos germinados e brotos comestíveis é um segmento que merece destaque na alimentação humana e está em franca expansão, o qual pode ser implantada inclusive no meio urbano. ${ }^{102}$ Devido a capacidade de brotos comestíveis em translocar e acumular elementos essenciais, além do seu elevado valor nutricional, estratégias que visem o aumento dos teores de elementos essenciais nesses produtos agrícolas vêm sendo almejadas. Przybysz et al..$^{35}$ avaliaram o enriquecimento de feijão mungo, alfafa, brócolis e rabanete cultivando brotos enriquecidos com Fe, usando soluções de Fe(III)-EDTA $\left(6,12,24\right.$ e $\left.36 \mathrm{mg} \mathrm{L}^{-1}\right)$. Verificou-se que a estratégia utilizada para o enriquecimento dos brotos com $\mathrm{Fe}$ aumentou significativamente a concentração total de $\mathrm{Fe}$ nos brotos avaliados, porém, dentre as espécies estudadas, o enriquecimento dos brotos de feijão mungo foi o menos eficaz com o aumento na concentração de Fe variando de 37 a $61 \%$. A maior bioacumulação de Fe foi observada nos rabanetes. Por outro lado, apesar da dinâmica e capacidade de germinação e crescimento dos brotos não serem alteradas pelo enriquecimento com $\mathrm{Fe}$, a formação de biomassa diminuiu significativamente para todas as espécies de brotos avaliadas. ${ }^{35}$

Em um segundo estudo realizado por Przybysz et al., ${ }^{36}$ o enriquecimento de brotos de feijão mungo, alfafa, brócolis e rabanete cultivados com $\mathrm{Mg}$, usando soluções de $\mathrm{MgSO}_{4} \cdot \mathrm{H}_{2} \mathrm{O}(50,100,200$ e $300 \mathrm{mg} \mathrm{L}^{-1}$ ), também foi avaliado. O enriquecimento com $\mathrm{Mg}$ foi mais eficiente em alfafa, no qual houve um aumento variando de 23 a $152 \%$ na concentração total. A concentração de $\mathrm{Mg}$ em brotos de brócolis e feijão mungo aumentou significativamente em relação ao grupo controle, porém, em menor porcentagem quando comparados às demais espécies de brotos avaliados, variando de 8 a $83 \%$ e 12 a $51 \%$, respectivamente. ${ }^{36}$

Blicharska et al. ${ }^{46}$ reportaram a possibilidade de cultivar brotos comestíveis em soluções enriquecidas com $\mathrm{Fe}, \mathrm{Cu}, \mathrm{Zn}, \mathrm{Ni}, \mathrm{Co}, \mathrm{Cd}$ e $\mathrm{Mn}$. As sementes foram cultivadas em celulose com adição dos metais em diferentes concentrações dos elementos de interesse. Os resultados sugeriram que sementes de lentilha e soja possuem a maior capacidade de acumular microelementos durante o processo de germinação. Por outro lado, a maior absorção de Ni foi observada para o feijão mungo, indicando que para a produção dos brotos, principalmente em solos enriquecidos é necessário o controle dos níveis de metais no solo de cultivo antes da comercialização desse produto. ${ }^{46}$

Brotos de soja também foram submetidos a um processo de enriquecimento com Fe. ${ }^{50}$ As sementes foram imersas em soluções com diferentes concentrações de $\mathrm{FeSO}_{4}\left(0-25 \mathrm{mmol} \mathrm{L}^{-1} \mathrm{FeSO}_{4}\right)$ durante $12 \mathrm{~h}$, germinadas por um período de 7 dias e regadas diariamente com soluções contendo a mesma concentração de Fe utilizada no procedimento de imersão. Analisaram-se as raízes e cotilédones, os quais apresentaram um aumento de 25 vezes na concentração de $\mathrm{Fe}$ quando comparados ao grupo controle..$^{50}$ Brotos de ervilha foram enriquecidos com $\mathrm{Zn}$, usando pulverização da planta com solução de $\mathrm{Zn}$ ou imersão das sementes em solução de $\mathrm{Zn}$ antes do cultivo. A pulverização da planta com solução de $\mathrm{ZnSO}_{4}$ foi mais efetiva para o aumento da concentração total de $\mathrm{Zn}$ na planta quando comparada a estratégia de imersão das sementes em solução de $\mathrm{ZnSO}_{4} \cdot{ }^{42}$ Esse elemento também foi adicionado a culturas de soja, no qual as sementes foram germinadas em solução de $\mathrm{Zn}\left(\mathrm{ZnSO}_{4}\right) \cdot{ }^{58}$ Nesse trabalho, as porcentagens de $\mathrm{Zn}$ bioacessível nos brotos de soja cultivados após a germinação das sementes em água e na presença de soluções contendo 10 e $20 \mathrm{mg} \mathrm{L}^{-1}$ de $\mathrm{Zn}$ foram 3,5; 3,8; e 5,2\%, respectivamente, revelando um aumento na bioacessibilidade elementar após germinação em solução mais concentrada de $\mathrm{Zn} .^{58}$

$\mathrm{O}$ enriquecimento de brotos com Se desperta grande interesse, sendo estudadas diversas alternativas de fortificação por cultivo de diferentes brotos comestíveis, tais como rabanete, ${ }^{49}$ brócolis, ${ }^{49}$ repolho, ${ }^{41}$ mostarda,${ }^{41}$ centeio,${ }^{41}$ soja ${ }^{48}$ feijão mungo,${ }^{48}$ trigo,${ }^{43}$ ervilha,${ }^{43}$ couve $^{54}$ e alho. ${ }^{37}$ Trolove et al..$^{49}$ desenvolveram um método para produção de brotos de rabanete roxo (Raphanus sativus L. cv. 'Sango'), rabanete verde (Raphanus sativus L.) e brócolis (Brassica oleracea L. var. italica Plenck) enriquecidos com Se, sendo suas sementes imersas em soluções de diferentes concentrações de $\mathrm{Se}$, preparadas com $\mathrm{Na}_{2} \mathrm{SeO}_{4}$. A adição de Se ao cultivo não alterou a concentração total de glucosinato ( $\beta$-tioglucosídeo $\mathrm{N}$-hidroxisulfato) nos brotos avaliados, porém, verificou-se que os rabanetes foram os mais viáveis para a produção de brotos enriquecidos, uma vez que, apresentaram maior potencial de acúmulo desse elemento, sendo ainda maior com o aumento do tempo de imersão das sementes. ${ }^{49}$ Plantas brássicas também foram enriquecidas com Se. ${ }^{40,41}$ Piekarska et al. ${ }^{40}$ conseguiram enriquecer sementes de plantas brássicas (repolho branco (Brassica oleracea var. capitata f. alba), brócolis (Brassica oleracea L. var. italica), mostarda (Sinapsis alba) e centeio (Secale cereale)) por imersão das sementes em solução de $\mathrm{Se}\left(\mathrm{SeO}_{2}\right)$ obtendo-se um aumento da concentração de Se de 4 para $382 \mathrm{mg} \mathrm{g}^{-1}$ sem alteração das características fisiológicas da planta. ${ }^{40}$

Bai et al..$^{48}$ avaliaram o acúmulo de Se na produção de brotos de soja (Glycine max) e de feijão mungo (Vigna radiata). Os brotos comestíveis foram cultivados pulverizando a planta com solução de diferentes concentrações de $\mathrm{Se}\left(\mathrm{Na}_{2} \mathrm{SeO}_{4}\right)$. Os brotos de soja apresentaram maior potencial de acúmulo de Se quando comparados aos brotos de feijão mungo. ${ }^{48}$ Meio enriquecido com diferentes concentrações de $\mathrm{Se}(\mathrm{IV})$ ou $\mathrm{Se}(\mathrm{VI})$ também foi aplicado para o cultivo de brotos de trigo (Triticum aestivum) e de ervilha verde (Pisum sativum). Os autores reportaram que a suplementação com $\mathrm{Se}(\mathrm{VI})$ favoreceu o acúmulo desse elemento na planta, sendo a concentração total de Se nos brotos de trigo e de ervilha verde cultivados na presença de $\mathrm{Se}$ (IV) 2,3 e 1,5 vezes, respectivamente, maior em relação ao cultivo dos brotos com $\mathrm{Se}(\mathrm{VI}) .^{43}$

Sistema de cultivo hidropônico com diferentes concentrações de $\mathrm{Se}(\mathrm{IV})$ foi aplicado para o enriquecimento de brotos de couve 
(Brassica oleracea var. alboglabra L.). ${ }^{54}$ A cromatografia líquida de alta eficiência em fase reversa (RP-HPLC, do inglês reversed phase high performance liquid chromatography) foi aplicada no estudo da distribuição e acúmulo de Se nos brotos de couve. Os estudos de especiação química indicaram que as formas predominantes das espécies de Se orgânico nos brotos de couve enriquecidos são SeMet e SeMeSeCys. Entretanto, períodos de cultivo superiores a 15 dias resultaram na diminuição da concentração de SeMet e SeMeSeCys, as quais foram possivelmente transformadas em outras espécies orgânicas de Se. ${ }^{54}$ Estudos de especiação química também foram aplicados a brotos de alho (Allium Sativum L.) enriquecidos com Se.$^{37}$ Os brotos de alho foram cultivados em solução nutritiva fortificada com $10 \mathrm{mg} \mathrm{L}^{-1}$ de $\mathrm{Se}(\mathrm{IV})$ e houve um acúmulo de $250 \mu \mathrm{g} \mathrm{g}^{-1}$ de Se nos brotos. As concentrações de $\mathrm{Na}_{2} \mathrm{SeO}_{3}$, metilselenocisteína (MeSeCys) e SeMet além de duas espécies desconhecidas de Se foram determinadas e verificou-se que MeSeCys foi a espécie de Se que apresentou maior acúmulo $(65 \%)$ nos brotos de alho enriquecidos. ${ }^{37}$

Além de brotos comestíveis, há outras fontes vegetais que merecem destaque quando se tratam de estratégias de enriquecimento, como é o caso de variedades de alface, tais como alface (Lactuca sativa L.) e alface-d'água (Pistia stratiotes L.). ${ }^{22-24,52,103}$ Os autores propuseram a fortificação das folhas com Mn, utilizando cultivo hidropônico. Houve um aumento significativo da concentração de Mn nas folhas, variando de 328 a $480 \mathrm{mg} \mathrm{kg}^{-1}$. Porém, o aumento na concentração de Mn diminuiu a concentração de $\mathrm{Zn}$ e o teor de clorofila nas folhas. ${ }^{22}$ Uma proposta inovadora foi publicada por Padash et al. ${ }^{23}$ na qual alfaces foram submetidas ao cultivo em substrato de areia com solução de $\mathrm{Zn}\left(\mathrm{ZnSO}_{4}\right)$, sendo que após 10 dias de cultivo foram adicionados fungos endofíticos (Piriformospora indica) a $1 \mathrm{~cm}$ distância abaixo das raízes de mudas. ${ }^{23}$ No que diz respeito a utilização de fungos endossimbióticos radiculares para a produção de plantas enriquecidas é importante destacar que há uma interação com as raízes de diferentes plantas com padrão endofítico sem invadir a endoderme e partes aéreas da planta. Estudos indicaram que fungos Piriformospora indica, além de favorecer a absorção de nutrientes e crescimento, estimularam a produção precoce de flores e sementes assim como permitiram que as plantas sobrevivessem sob condições de estresses bióticos e abióticos. ${ }^{104,105}$ Sendo assim, os resultados do cultivo de alface com adição desses fungos ao cultivo indicaram um aumento de $45 \%$ da concentração de $\mathrm{Zn}$ no tratamento com a presença dos fungos. No entanto, verificou-se uma relação antagônica entre $\mathrm{Zn}$ e Fe. ${ }^{23}$

$\mathrm{O}$ uso de métodos de vermicompostagem com $\mathrm{Cu}, \mathrm{Ni}$ e $\mathrm{Zn}$ foi também proposto para fortificação de alfaces. ${ }^{52}$ Observaram que o cultivo em solo com maiores teores do vermicomposto enriquecido com metais diminuiu o crescimento das folhas. As plantas cultivadas em solo enriquecido apresentaram maior concentração de $\mathrm{Cu}$ e Ni na raiz, apenas o Zn apresentou maior concentração nas folhas após o enriquecimento. ${ }^{52}$

$\mathrm{O}$ efeito do enriquecimento com Se na biodisponibilidade de $\mathrm{Cu}$, $\mathrm{Fe}, \mathrm{Mn}, \mathrm{Mo}$ e $\mathrm{Zn}$ foi avaliado em alfaces enriquecidas com esse elemento. Em estudos realizados por da Silva et al.,${ }^{20}$ as plantas de alface foram cultivadas em meio com adição de 25 e $40 \mu \mathrm{mol} \mathrm{L}^{-1}$ de Se(IV) ou $\mathrm{Se}(\mathrm{VI})$ e um período total de cultivo correspondente a 28 dias, no qual verificou-se que a adição de $\mathrm{Se}(\mathrm{VI})$ à solução de cultivo favoreceu a absorção de Se pela planta quando comparado ao enriquecimento com $\mathrm{Se}(\mathrm{IV})$. O enriquecimento com $\mathrm{Se}$ (VI) favoreceu a acumulação de Mo nas plantas. A adição das diferentes espécies de Se à solução de cultivo diminuiu significativamente a absorção de $\mathrm{Cu}$ e Fe pelas plantas, em contraste, o acúmulo de $\mathrm{Zn}$ e Mn não foi alterado pela adição de $\mathrm{Se}(\mathrm{IV})$ ou $\mathrm{Se}(\mathrm{VI}) .{ }^{20} \mathrm{~A}$ bioacessibilidade e especiação de $\mathrm{Se}$ em alfaces enriquecidas cultivadas hidroponicamente em soluções suplementadas com $\mathrm{Se}(\mathrm{IV})$ e Se(VI) também foi estudada. ${ }^{26}$ Os autores reportaram que o enriquecimento com $\mathrm{Se}(\mathrm{VI})$ favoreceu o acúmulo de Se na planta quando comparado ao cultivo com adição de Se(IV). O mesmo foi observado por Hawrylak-Nowak. ${ }^{28}$ Após procedimentos de digestão simulada in vitro, alfaces cultivadas em solução contendo $\mathrm{Se}(\mathrm{IV})$ uma fração significativa de Se foi biotransformado em espécies orgânicas desse elemento, tais como SeMet enquanto para o cultivo com adição de $\mathrm{Se}(\mathrm{VI})$ a maior fração da concentração total de $\mathrm{Se}$ correspondia a espécies inorgânicas de Se. ${ }^{26}$ Por fim, estudos recentes de biofortificação de alface com Se através de cultivos hidropônicos em solução com $\mathrm{Se}(\mathrm{IV})$ e adição de ácido salicílico, indicaram que com a adição de ácido salicílico à solução nutritiva houve um aumento da eficiência do enriquecimento de alfaces. ${ }^{27}$

O enriquecimento com Se também tem sido estudado para outros alimentos, além dos brotos comestíveis, tais como tomate (Solanum lycopersicum), ${ }^{30,62}$ pepino (Cucumis sativus L.), ${ }^{30}$ alface (Lactuca sativa L.), ${ }^{26-28,30}$ figueira da índia (Opuntia fícus-indica), ${ }^{61}$ alho (Allium sativum), ${ }^{29-31,106}$ batata (Solanum tuberosum L.), ${ }^{34}$ soja (Glycine max), ${ }^{60}$ brócolis (Brassica oleracea var. itálica), ${ }^{107}$ nabo (Brassica rapa),${ }^{60}$ canola (Brassica napus L.), ${ }^{32}$ cebola (Allium cepa),${ }^{51}$ cenoura (Daucus carota) ${ }^{53}$ Tomates foram cultivados hidroponicamente com Se, avaliando a produção, composição e maturação dos frutos. A solução nutritiva foi suplementada com $1 \mathrm{mg} \mathrm{L}^{-1} \mathrm{de} \mathrm{Se}(\mathrm{VI})$ e os frutos produzidos foram comparados ao grupo controle. Os resultados indicaram a absorção e translocação de Se, sendo que a concentração de Se nas folhas foi aproximadamente 3 vezes maior que nos frutos. Adicionalmente, os autores mostraram que o consumo de $100 \mathrm{~g}$ dos tomates enriquecidos fornece níveis adequados desse elemento na nutrição humana sem atingir níveis tóxicos de ingestão de Se. ${ }^{62}$

Tomates e pepinos enriquecidos com Se foram produzidos utilizando turfa fortificada com concentrações de $\mathrm{Se}(\mathrm{VI})$, variando de 0 a $1000 \mathrm{mg} \mathrm{kg}^{-1}$. Posteriormente, as plantas foram transferidas para o solo de cultivo não fortificado. O cultivo em turfa enriquecida com $\mathrm{Se}(\mathrm{VI})$ não alterou o desenvolvimento das plantas, sendo obtidas concentrações de Se na parte comestível da planta de 2 (tomate) a 9 (alface) vezes maior quando comparadas ao grupo controle. ${ }^{25}$

Em um estudo realizado por Sharma et al. ${ }^{32}$ sobre o efeito do $\mathrm{Se}(\mathrm{IV})$ ou $\mathrm{Se}$ (VI) adicionados ao solo arenoso alcalino para o cultivo de folhas de canola, os resultados evidenciaram maior eficiência na absorção e translocação de Se(VI), embora o crescimento das folhas tenha sido negativamente afetado por essa espécie de Se. É importante destacar que o acúmulo de Se nas folhas aumentou significativamente a peroxidação lipídica e o teor de clorofila, vitamina C e aminoácidos, enquanto houve uma diminuição do conteúdo de fenóis, açúcares totais solúveis e amido. ${ }^{32}$

Na produção de raízes tuberosas enriquecidas, Kápolna et al ${ }^{53}$ avaliaram o efeito da aplicação foliar de Se(IV) ou Se(VI) no enriquecimento de cenouras. As sementes foram germinadas em vermiculita e, posteriormente, cultivadas em uma mistura de solo e areia (3:1). A pulverização com solução contendo $100 \mu \mathrm{g} \mathrm{mL} \mathrm{m}^{-1}$ de Se foi mais eficiente ao utilizar espécies de $\mathrm{Se}(\mathrm{VI})$ para o enriquecimento das raízes. Além disso, estudos de especiação química indicaram que nas cenouras produzidas em ambas as condições de cultivo as formas orgânicas de Se predominantes foram SeMet e $\gamma$-glutamil-selenio-metil-selenocisteína ( $\gamma$-GluMeSeCys) e a biotransformação das espécies inorgânicas de Se utilizadas para a aplicação foliar foi favorecida. ${ }^{53}$

Tsuneyoshi et al. ${ }^{108}$ avaliaram estratégias de cultivo hidropônico para a produção de alho enriquecido com Se. Os autores reportaram que a presença de $\mathrm{SO}_{4}{ }^{2-}$ na solução nutritiva inibiu a absorção de $\mathrm{Se}(\mathrm{VI})$ pela planta, porém ao ser utilizada uma solução nutritiva na ausência de $\mathrm{SO}_{4}{ }^{2-}$ o acúmulo de $\mathrm{Se}$ nas mudas de alho foi favorecido. ${ }^{108}$ Essa observação também foi reportada por Barack e Goldman ${ }^{51}$ no cultivo de cebolas. Além disso, as análises de especiação química por cromatografia líquida de alta eficiência acoplada a espectrometria de massas com plasma indutivamente acoplado (HPLC-ICP-MS, 
do inglês high performance liquid chromatography / inductively coupled plasma mass spectrometry) permitiram identificar as espécies orgânicas de Se metabolizadas, tais como SeMeSeCys, SeMet e $\gamma$-GluMeSeCys. ${ }^{108}$ Outra proposta foi o cultivo de alhos em solo com adição de fungos simbióticos (micorriza) e Se(VI). A adição dos fungos ao solo enriquecido com $\mathrm{Se}(\mathrm{VI})$ aumentou $13 \%$ a concentração desse elemento, quando comparada com os alhos produzidos em solo com adição de $\mathrm{Se}(\mathrm{VI})$ e sem fungos. É importante salientar que as espécies de Se não foram alteradas, independentemente do cultivo. ${ }^{30}$

É interessante notar que os diversos trabalhos de enriquecimento também evidenciam as diferentes reações antagônicas entre os elementos presentes no solo de cultivo. Como é o caso da absorção e transporte de $\mathrm{Fe}$ e $\mathrm{Cu}$ em plantas. ${ }^{109} \mathrm{O}$ mecanismo de competição na translocação elementar entre $\mathrm{Cu}$ e Fe não é bem elucidado, porém a similaridade entre o raio iônico desses elementos também tem sido apontada com a possível causa para tais competições. ${ }^{110}$ Estudos indicaram também que em plantas com folhas nos primeiros dias de crescimento, o enriquecimento com $\mathrm{Ca}$ promoveu uma redução na concentração de $\mathrm{Mg}$ em todos os vegetais enriquecidos, confirmando o antagonismo entre Ca e Mg. ${ }^{109}$ Em estudos de biofortificação de sementes de ervilha, Pandey et al. ${ }^{55}$ sugeriram que estratégias de aplicação foliar são efetivas para a produção de legumes enriquecidos com $\mathrm{Zn}$, uma vez que, elevadas concentrações de fertilizantes contendo $\mathrm{N}$ e P no solo diminuem a absorção de $\mathrm{Zn}$ e, consequentemente, plantas cultivadas nessas áreas apresentam deficiência de $\mathrm{Zn}$ principalmente nas sementes. ${ }^{55}$

O antagonismo entre Se e S também já foi observado para plantas, pois esses elementos competem pelos sítios de absorção nas vias metabólicas. ${ }^{111}$ Alguns estudos indicam um efeito antagônico entre o Se(IV) e a absorção de fosfato em plantas. ${ }^{112,113}$ No metabolismo da planta, uma fração de Se(VI) absorvida é reduzida a Se(IV) e absorvido de forma passiva pelas células das plantas. O Se(IV) compete pelos sítios de absorção nos transportadores de fosfato, devido as suas similaridades químicas, aumentando a concentração de $\mathrm{P}$ nas partes inferiores da planta (raiz e cotilédone) e favorecendo o transporte de Se para a parte aérea (caule). ${ }^{114}$ Por outro lado, a fração de Se(VI) que não foi reduzida utiliza os mesmos transportadores de membrana do sulfato, ${ }^{111,115}$ justificando a diminuição significativa na concentração de $\mathrm{S}$ no caule ao enriquecer o solo de cultivo com $\mathrm{Se}(\mathrm{VI})$, devido à inibição competitiva entre essas espécies químicas.

\section{Fungos comestíveis enriquecidos por meio de cultivo}

O reino dos fungos compreende mais de um milhão de espécies, entre as quais destacam-se os cogumelos, que apresentam grande importância para o ecossistema, sendo capazes de biodegradar substratos orgânicos. Existem aproximadamente 10 mil espécies conhecidas de cogumelos, das quais 50 são tóxicas, 50 a 200 utilizadas em práticas medicinais e 700 são comestíveis, entre as espécies comestíveis apenas 25 são comercialmente cultivadas. No Brasil, as principais espécies comestíveis cultivadas são Agaricus bisporus, Lentinula edodes e Pleurotus spp. ${ }^{116}$

O consumo de cogumelos comestíveis é um segmento que merece destaque na alimentação humana e está em franca expansão. ${ }^{117}$ Os cogumelos são alimentos com alto valor nutricional, consumidos no mundo todo e apreciados não apenas por seu sabor e textura, mas também devido à sua relação com propriedades terapêuticas e medicinais, que vão desde o estímulo ao sistema imunológico, combate ao estresse físico e emocional, até a redução do colesterol e auxílio no combate a alguns tipos de câncer. ${ }^{118}$ Os cogumelos também produzem uma grande variedade de metabólitos secundários, como ácidos orgânicos, alcaloides, esteroides, compostos fenólicos e possuem propriedades antioxidantes..$^{88}$
O gênero Pleurotus tem despertado grande interesse por parte da comunidade médica e científica, devido ao alto valor nutricional dos cogumelos, por possuir baixas calorias, e ser boa fonte de proteínas, carboidratos, vitaminas, cálcio e ferro, além de apresentar baixo custo e importantes propriedades medicinais. Os produtos derivados dos cogumelos Pleurotus possuem propriedades antitumorígenas, modulam os níveis de colesterol, previnem a agregação plaquetária nas artérias evitando doenças cardiovasculares e combatem o vírus da hepatite $\mathrm{C}$, além de apresentarem propriedades antibacterianas. ${ }^{119}$

Porém, os fungos possuem características distintas das plantas e não são capazes de utilizar diretamente a energia solar. O desenvolvimento dos fungos depende da absorção de nutrientes de um material orgânico, no qual esses organismos são cultivados. É possível classificar as técnicas de cultivo de cogumelos comestíveis como uma agricultura sustentável que apresentam diversas vantagens, entre as quais destacam-se o uso de produtos residuais agrícolas, obtenção de altos níveis de produção por área cultivada e após a colheita o substrato residual pode ser utilizado adequadamente como condicionador do solo. ${ }^{120}$

Na natureza, os fungos propagam-se através da produção de esporos e quando se encontram em um ambiente apropriado ramificam-se para colonizar o substrato com teias finas de filamentos, constituindo o corpo vivo inicial do fungo (micélio). No cultivo de cogumelos comestíveis em pequena escala, o cogumelo deve ser capaz de colonizar o substrato antes de outros fungos e bactérias. Sendo assim, para iniciar o processo de cultivo, um micélio isento de quaisquer bactérias e/ou outros fungos deve ser pré-cultivado dando origem a "semente" de cogumelos, a qual favorece o desenvolvimento do cogumelo cultivado em comparação com outros fungos possivelmente presentes em substratos orgânicos, os quais podem ser compostos por grãos de cereal, serragem, palha, casca de café, entre outros. ${ }^{9,121-123}$ No início do cultivo deve ser induzida a colonização micelial e para realizar esse processo a semente de cogumelo é inoculada em um substrato orgânico que será colonizado pelo micélio utilizando os nutrientes presentes no substrato e disponíveis no substrato de cultivo. ${ }^{9}$ Após o período de colonização micelial ( 15 dias) e completa colonização do substrato, o micélio é capaz de produzir a parte comestível do fungo, ou seja, o cogumelo também denominado corpo de frutificação ou basidiocarpo.

Durante o período de formação do cogumelo, alguns elementos presentes no substrato orgânico podem ser absorvidos pelo micélio e, posteriormente, bioacumulados nos corpos de frutificação. ${ }^{10,45,90} \mathrm{~A}$ bioacumulação é favorecida à medida que os cogumelos absorvem água presente no substrato orgânico, e consequentemente os nutrientes, incluindo espécies elementares. Posteriormente, a translocação desses elementos promove a bioacumulação deles nos corpos de frutificação. A translocação dos elementos do micélio até os corpos de frutificação pode ser governada pelo fluxo constante de água. A absorção e bioacumulação de nutrientes são favorecidas pelo processo natural de evaporação de água através da superfície dos corpos de frutificação dos cogumelos. ${ }^{120}$

Os micélios podem servir como filtros biológicos, uma vez que, os cogumelos consistem em uma grande biomassa com textura resistente que os tornam potenciais biossorventes. ${ }^{124}$ Além disso, estudos realizados por Gharieb et al. ${ }^{125}$ indicaram que a absorção intracelular e extracelular é o principal mecanismo que os fungos utilizam para remoção de metais de um meio de cultura líquido. Além disso, os autores verificaram que a absorção intracelular permitiu o acúmulo de $\mathrm{Cd}$, enquanto a absorção extracelular o de $\mathrm{Cr} .{ }^{125}$ No que diz respeito à absorção e bioacumulação de Se, sabe-se que uma pequena fração do Se(IV) absorvido pelos cogumelos é dependente do metabolismo do fungo, enquanto a maior fração desse íon é absorvida por vias de transporte passivo. ${ }^{72}$ Nesse sentido, sabe-se que o transporte de Se(IV) 
através da membrana plasmática é o primeiro passo do metabolismo do Se(IV), ${ }^{67}$ porém o mecanismo de captação de Se pelos cogumelos ainda permanece incerto.

Sendo os cogumelos organismos bioacumuladores, é possível realizar o enriquecimento elementar através de etapas que antecedem o início da formação dos corpos de frutificação, ${ }^{9,89,90}$ porém, alguns estudos indicaram que a concentração de um determinado elemento nos cogumelos depende, principalmente, da espécie química do elemento e da fisiologia do cogumelo. Além disso, a composição do substrato e o ciclo de frutificação também podem influenciar a bioacumulação elementar., ${ }^{9,73,89,90,126}$

$\mathrm{Na}$ natureza, os cogumelos apresentam diversos elementos essenciais em sua composição, tais como $\mathrm{Cu}, \mathrm{Fe}, \mathrm{Zn}$ e $\mathrm{Se}$, e devido ao elevado potencial bioacumulador e a escassez de fontes vegetais de $\mathrm{Se}$, os cogumelos tem sido alvo de estudos voltados, principalmente, ao desenvolvimento de estratégias que visem o enriquecimento desse alimento com esse elemento essencial para a nutrição humana. ${ }^{9,73,90}$ Nos estudos de enriquecimento de cogumelos com Se, a estratégia comumente utilizada para promover o aumento dos níveis desse elemento no corpo de frutificação dos fungos é a adição de espécies inorgânicas de $\mathrm{Se}$, principalmente $\mathrm{Se}(\mathrm{IV})$ na forma de selenito de sódio $\left(\mathrm{Na}_{2} \mathrm{SeO}_{3}\right)$ ao substrato orgânico. ${ }^{9,65,82}$

Em cogumelos Agaricus bisporus e Letinula edodes cultivados em substratos enriquecidos com Se(IV), verificou-se que SeMet foi a principal espécie de Se biodisponível, havendo um aumento na concentração de Se no micélio e no corpo de frutificação dos cogumelos. ${ }^{64,78}$ Adicionalmente, Werner e Beelman ${ }^{63}$ demonstraram a eficiência do enriquecimento de Agaricus bisporus com $\mathrm{Se}$ quando o substrato foi suplementado com solução aquosa de $\mathrm{Se}$ (IV) em diferentes concentrações e verificou-se que a absorção de Se aumentou linearmente com a concentração de Se adicionada ao substrato. ${ }^{63}$ Silva et al. ${ }^{9}$ avaliaram o enriquecimento de cogumelos Pleurotus ostreatus através do cultivo em substrato de casca de café com diferentes concentrações de $\mathrm{Na}_{2} \mathrm{SeO}_{3}$, no qual altas concentrações de Se alteraram a eficiência biológica na biodegradação do substrato orgânico, sendo $51 \mathrm{mg} \mathrm{kg}^{-1}$ a maior concentração de $\mathrm{Se}(\mathrm{IV})$ adicionada ao substrato de cultivo que não alterou significativamente as características morfológicas do corpo de frutificação dos cogumelos. ${ }^{9}$

Bhatia et al. ${ }^{87}$ estudaram a bioacessibilidade de Se em cogumelos Pleutorus florida enriquecidos com Se cultivando-os em substrato composto por resíduos agrícolas, contendo trigo enriquecido com esse elemento. Através do método de digestão gastrointestinal simulada in vitro estimou-se a bioacessibilidade de Se, avaliando a fração solúvel (bioacessível). Os resultados obtidos mostraram que $75 \%$ da concentração total de Se presente nos corpos de frutificação dos cogumelos estudados correspondeu a espécies solúveis de Se. ${ }^{87}$ Serafin et al. ${ }^{91}$ realizaram estudos visando a avaliação da interação de Se com proteínas e observaram que o Se foi incorporado à biomassa de cogumelos da espécie Pleurotus ostreatus, uma vez que esse elemento foi encontrado associado à membrana (44\%) e parede celular (56\%), onde a incorporação de Se às proteínas fúngicas revelou um grande potencial para melhorar o valor nutricional dos cogumelos após o enriquecimento. ${ }^{91}$ Adicionalmente, em cogumelos Pleurotus ostreatus enriquecidos com Se foi avaliada a biodisponibilidade desse elemento aplicando-se métodos in vivo, e os resultados obtidos mostraram que os maiores níveis de absorção de Se foram verificados em ratos alimentados com cogumelos enriquecidos com Se, ao comparar esses resultados com aqueles obtidos para ratos alimentados com dieta com adição de $\mathrm{Na}_{2} \mathrm{SeO}_{3} \cdot{ }^{90}$

Zhao et $a l .{ }^{73}$ e Silva et al..$^{90}$ estudaram o enriquecimento de cogumelos Ganoderma lucidum e Pleurotus ostreatus, e verificaram que a porcentagem de Se absorvida variou de 20 a $30 \%$ e 16 a $34 \%$, respectivamente. Por outro lado, Silva et al. ${ }^{9}$ e Savic et al. ${ }^{92}$ verificaram que elevadas concentrações de Se adicionadas ao substrato de cultivo de cogumelos Pleurotus alteraram a morfologia do corpo de frutificação formando-se estipes mais finos e chapéus com curvaturas pouco definidas.

Niedzielski et al..$^{85}$ e Savic et al..$^{92}$ avaliaram a adição de soluções de $\mathrm{Na}_{2} \mathrm{SeO}_{3}$ e $\mathrm{Na}_{2} \mathrm{SeO}_{4}$ ao substrato de cultivo no enriquecimento de diferentes espécies de cogumelos medicinais (Agrocybe aegerita, Hericium erinaceus e Ganoderma lucidum) e comestíveis (Pleurotus ostreatus). Savic et al. ${ }^{92}$ verificaram que as espécies de $\mathrm{Se}(\mathrm{IV}) \mathrm{e}$ $\mathrm{Se}(\mathrm{VI})$ foram efetivamente absorvidas dos substratos e acumuladas nos corpos de frutificação. Porém, a concentração de Se total adicionando-se $\mathrm{Se}(\mathrm{IV})$ ao substrato de cultivo foi maior quando comparado a adição de Se(VI). A avaliação do crescimento micelial indicou que adição de concentrações acima de $50 \mathrm{mg} \mathrm{L}^{-1} \mathrm{de} \mathrm{Se}(\mathrm{VI})$ ao substrato induziu a um maior crescimento do micélio e possivelmente um maior acúmulo de Se.92

De acordo com Brown e Shrift ${ }^{99}$ e Zhao et $_{\text {al. }}{ }^{73}$ organismos bioacumuladores de Se podem absorver Se inorgânico, incorporando e transformando as formas inorgânicas em SeMeSeCys e Se-cistatione. Estudos realizados em fungos indicaram que cogumelos enriquecidos possuem diferentes espécies de Se, tais como selenocisteína (SeCys), SeMet, SeMeSeCys e Se(IV). ${ }^{127}$ Em estudos de especiação química em cogumelos Agaricus bisporus cultivados em substrato enriquecido com Se realizados por Huerta et al. ${ }^{64}$ os cogumelos cultivados em substratos enriquecidos com Se diferiram não apenas na concentração de Se total, mas também nas espécies de Se presentes nos cogumelos, nos quais aqueles que foram cultivados em substrato enriquecido possuíram SeMet incorporada a estruturas proteicas. ${ }^{64}$

Solovyev et al. ${ }^{66}$ cultivaram cogumelos em substrato orgânico a base de agro-resíduos de palha de trigo enriquecido com Se. Dentre as espécies de cogumelos avaliadas (Pleurotus sajor-caju, Pleurotus ostreatus, Pleurotus citrinopileatus, Agaricus bisporus e Volvariella volvacea) a espécie $A$. bisporus apresentou a maior concentração de Se $\left(1396 \mu \mathrm{g} \mathrm{g}^{-1}\right) .{ }^{66} \mathrm{Em}$ cogumelos Calocybe indica verificaram-se que o cultivo em substrato a base de palha de trigo com adição de diferentes concentrações de Se(IV) favoreceu a interação de Se a proteínas $(56 \%$ a $68 \%)$, polissacarídeos $(22 \%$ a $29 \%)$ e ácidos nucleicos $(1,4 \%$ e $2,7 \%){ }^{70}$

Carrasco-Gonzalez et al. ${ }^{96}$ avaliaram o efeito do enriquecimento com Se nas características micológicas de Pleurotus ostreatus e nas capacidades antioxidantes. Enquanto os corpos de frutificação provenientes da $2^{\mathrm{a}}$ e $3^{\mathrm{a}}$ floração em substrato com elevada concentração de Se $\left(17.5 \mathrm{mg} \mathrm{kg}^{-1}\right)$ possuíram a mesma capacidade antioxidante, nos cogumelos cultivados em substrato com adição de $5,8 \mathrm{mg} \mathrm{kg}^{-1}$ de Se aqueles provenientes da $2^{\mathrm{a}}$ floração apresentaram maior capacidade antioxidante quando comparados a $3^{\text {a }}$ floração. ${ }^{96}$ Os efeitos do enriquecimento com Se nas atividades antioxidantes também foram estudadas para as espécies Pleurotus sajor-caju e Volvariella volvacea cultivadas em agro-resíduos orgânicos provenientes da colheita de trigo e arroz enriquecidos com Se. Além de aumentar a concentração total de Se nos corpos de frutificação, sendo 8,4 (P. sajor-kaju) e 6,3 (V. volvacea) vezes maior quando comparada ao grupo controle, o enriquecimento também aumentou significativamente a atividade antioxidante nos cogumelos no que diz respeito a concentração total de fenol, atividade oxidante total, eliminação de 2,2-difenil-1-picril-hidrazil, quelação de metais e atividade inibidora de peroxidação lipídica. ${ }^{98}$ Estudos do efeito do Se na eliminação de radicais livres em cogumelos do gênero Ganoderma indicaram que o enriquecimento com Se também desempenha um papel importante no aumento das atividades antioxidantes dos extratos de polissacarídeos provenientes de cogumelo rei (Ganoderma lucidum) cultivado em meio suplementado com $\mathrm{Na}_{2} \mathrm{SeO}_{3} \cdot{ }^{75}$ 
Hu et al. ${ }^{71}$ compararam o enriquecimento de cogumelos cultivados em meio suplementado com Se(IV), Se(VI) ou SeMet. A adição de $40 \mu \mathrm{g} \mathrm{g}^{-1}$ de $\mathrm{Se}(\mathrm{IV})$ ou $\mathrm{Se}(\mathrm{VI})$ ao substrato aumentou significativamente a concentração total de Se nos corpos de frutificação obtendo-se 130,9 e $128,1 \mu \mathrm{g} \mathrm{g}^{-1}$ de Se, respectivamente. Porém, a suplementação com Se proveniente de SeMet diminuiu a eficiência biológica no cultivo, além da concentração desse elemento nos corpos de frutificação ser aproximadamente $50 \%$ menor quando comparada ao cultivo com adição de espécies inorgânicas de Se ao substrato orgânico. ${ }^{71}$

Em cogumelos shiitake (Lentinula edodes) enriquecidos com Se foram feitos estudos de especiação química por HPLC-ICP-MS e cromatografia líquida de alta eficiência acoplada a espectrometria de massas com fonte de ionização electrospray (HPLC-ESI-MS, do inglês high performance liquid chromatography/electrospray ionization tandem mass spectrometry). Os resultados mostraram SeMet associado a proteínas solúveis em água e de elevada massa molecular. ${ }^{80}$

Os cogumelos shitake e Pleurotus ostreatus também foram cultivados em substrato a base de lascas de madeira enriquecidos com diferentes concentrações de $\mathrm{Se}(\mathrm{IV}), \mathrm{Se}(\mathrm{VI})$ ou leveduras selenizadas..$^{81,97}$ Zhou et al..$^{81}$ também avaliaram recentemente o efeito do enriquecimento de cogumelos shiitake nas espécies químicas de Se acumuladas. A determinação de diferentes espécies de $\mathrm{Se}$ ( $\mathrm{Se}(\mathrm{IV})$, $\mathrm{Se}(\mathrm{VI}), \mathrm{SeMet}, \mathrm{MeSeCys}$ e $\mathrm{SeCys}_{2}$ ) foi realizada por espectrometria de fluorescência atômica acoplada a cromatografia líquida irradiação UV com geração de hidreto (LC-UV-HG-AFS, do inglês liquid chromatography-UV irradiation-hydride generation-atomic fluorescence spectrometry), observando que SeMet foi a espécie de Se predominante nos cogumelos enriquecidos. ${ }^{81}$

Em champignon (Agaricus bisporus) enriquecidos com Se, foi determinada maior concentração de SeCys do que SeMet e MeSeCys. ${ }^{67}$ Outro trabalho realizou também a especiação química em cogumelos champignon usando espectroscopia de absorção de raios $\mathrm{X}$ na região próxima à borda (XANES, do inglês $X$-ray absorption near edge structure). Os espectros de absorção de raios-X da borda $\mathrm{K}$ do Se indicaram que nos cogumelos enriquecidos a espécie Se-metil L-selenocisteína é a forma predominante e, portanto, o Se acumulado nesses cogumelos é altamente bioacessível. ${ }^{68}$

Os cogumelos do gênero Pleurotus também foram alvo de estudos envolvendo enriquecimento simultâneo com Se(IV), Se(VI) e Zn assim como a avaliação da composição fenólica e propriedades antioxidantes dos cogumelos enriquecidos. A espécie $P$. ostreatus apresentou maior potencial para bioacumular Se $\left(109,74 \pm 11,06 \mathrm{mg} \mathrm{kg}^{-1}\right)$, enquanto a espécie $P$. eryngii maior bioacumulação de $\mathrm{Zn}\left(85,95 \pm 2,22 \mathrm{mg} \mathrm{kg}^{-1}\right)$. Os resultados indicaram que a suplementação simultânea com Se e Zn no substrato de cultivo pode ativar a síntese de compostos fenólicos e ácido ascórbico, elevando o teor de compostos fenólicos nos corpos de frutificação e melhorando as propriedades antioxidantes dessas espécies de cogumelos em comparação com o grupo controle. ${ }^{86}$ Yan et al. ${ }^{95}$ avaliaram as atividades antioxidantes e antitumorais em ratos alimentados com cogumelos Pleurotus ostreatus enriquecidos com Se e Zn. Ocorreu uma diminuição do número de nódulos tumorais nos pulmões dos animais alimentados com cogumelos enriquecidos, sendo essa dieta mais eficaz no aumento das atividades antioxidantes e antitumorais quando comparados ao tratamento apenas com $\mathrm{Na}_{2} \mathrm{SeO}_{3}$ e $\mathrm{ZnSO}_{4}{ }^{95}$

As espécies Ganoderma lucidum e Agaricus bisporus também foram utilizadas no desenvolvimento de métodos de enriquecimento simultâneo de cogumelos com $\mathrm{Cu}$, Se e Zn. ${ }^{65,74}$ Os cogumelos $A$. bisporus foram cultivados em substrato orgânico com adição de diferentes concentrações de $\mathrm{Na}_{2} \mathrm{SeO}_{3}, \mathrm{Na}_{2} \mathrm{SeO}_{4}, \mathrm{CuO}_{4} \mathrm{Se}$ e $\mathrm{Zn}\left(\mathrm{NO}_{3}\right)_{2}$, os quais bioacumularam até 17,8 $\pm 1,1(\mathrm{Se}), 39,1 \pm 4,3(\mathrm{Cu})$ e $50,7 \pm 4,4(\mathrm{Zn}) \mathrm{mg} \mathrm{kg}^{-1}$ quando cultivados com todos os elementos de interesse. ${ }^{65}$ Em um estudo similar de enriquecimento simultâneo de cogumelos da espécie G. lucidum verificou-se que os cogumelos foram capazes de biacumular até 19,8 $\pm 1,8(\mathrm{Se}), 31,3 \pm 12,9(\mathrm{Cu})$ e $52,5 \pm 10,9(\mathrm{Zn}) \mathrm{mg} \mathrm{kg}^{-1} \cdot{ }^{74}$

Por outro lado, o enriquecimento de cogumelos comestíveis com outros elementos essenciais ainda é escasso na literatura. ${ }^{65,69,74,77,81,83,86,95}$ Ogidi et al. $^{83}$ avaliaram a absorção de Fe em seis espécies de cogumelos comestíveis do gênero Pleurotus (Pleurotus ostreatus; Pleurotus cornucopiae; Pleurotus djamor; Pleurotus pulmonarius, and Pleurotus djamor v. roseus), os quais foram cultivados em substrato a base de capim baquiária (Urochloa decumbens) com adição de diferentes concentrações de Fe. $\mathrm{O}$ aumento da concentração de Fe no substrato de cultivo inibiu o crescimento micelial e o desenvolvimento dos corpos de frutificação. As espécies Pleurotus ostreatus e Pleurotus pulmonarius mostraram o maior potencial bioacumulador, sendo que os cogumelos cultivados em substrato com adição de $1000 \mathrm{mg} \mathrm{kg}^{-1}$ (Fe) apresentaram 88,54 e 83,49 $\mu \mathrm{g} \mathrm{g}^{-1}$ de Fe, respectivamente..$^{83} \mathrm{~A}$ bioacumulação de $\mathrm{Ca}$ foi avaliada em cogumelos das espécies Pleurotus ostreatus e Lentinus squarrosulus cultivados em diferentes composições dos substratos a base de casca de coco ou fibra de palmiste suplementados com casca de ovo de frango, concha de caracol, osso bovino ou sais de $\mathrm{Ca}\left(\mathrm{CaCl}_{2}, \mathrm{CaCO}_{3}, \mathrm{CaO}, \mathrm{CaHPO}_{4}\right.$ ou $\left.\mathrm{Ca}(\mathrm{OH})_{2}\right)$. Os cogumelos das espécie $P$. ostreatus apresentaram a maior concentração de $\mathrm{Ca}\left(5,97 \mathrm{mg} \mathrm{g}^{-1}\right)$ quando cultivados em substrato a base de casca de coco suplementado com casca de ovo e concha de caracol, enquanto os cogumelos L. squarrosulus cultivados em substrato a base de fibra de palmiste suplementada com casca de ovo, concha de caracol e osso bovino apresentaram a maior concentração total de $\mathrm{Ca}\left(5,11 \mathrm{mg} \mathrm{g}^{-1}\right)$. Os estudos indicaram que o uso de resíduos animais ricos em Ca para a suplementação de substratos de cultivo de cogumelos comestíveis pode ser uma boa alternativa para a produção de cogumelos comestíveis enriquecidos com Ca. ${ }^{79}$ Por fim, estudos avaliando a capacidade de cogumelos Pleurotus ostreatus em acumular lítio (Li), e a acessibilidade das espécies de Li formadas em comparação com o carbonato de lítio $\left(\mathrm{Li}_{2} \mathrm{CO}_{3}\right)$, frequentemente usado como medicamento psiquiátrico, indicou que esses cogumelos enriquecidos podem ser uma fonte alternativa de Li para tais fármacos. ${ }^{128,129}$

Porém, em estudos de enriquecimento de organismos bioacumuladores, deve-se também avaliar o potencial desses organismos bioacumularem elementos tóxicos presentes no substrato de cultivo. $\mathrm{O}$ potencial de absorção de cogumelos Termitomyces microcarpus para $\mathrm{Cu}, \mathrm{Pb}, \mathrm{Cd}$ e As foi estudado por Zhang et al. ${ }^{130}$ os quais obtiveram como resultados 135, 13, 65 e 1,6 $\mathrm{mg} \mathrm{kg}^{-1}$, respectivamente. Em estudos realizados por Mleczek et al., ${ }^{129}$ as espécies de cogumelos Boletus edulis apresentaram elevados potenciais de bioacumulação de $\mathrm{Cu}, \mathrm{Cd}, \mathrm{Zn}$ e $\mathrm{Mn}$, enquanto Isildak et al. ${ }^{131}$ relataram que que outra espécie de cogumelos Boletus (Boletus badius) possui maior potencial de bioacumulação para $\mathrm{Pb}\left(0,448 \mathrm{mg} \mathrm{kg}^{-1}\right)$ quando comparada a espécie Boletus edulis. Por outro lado, cogumelos Pleurotus ostreatus apresentam um potencial de absorção máximo para $\mathrm{Cd}, \mathrm{Hg}$ e Zn, porém a absorção e acumulação de $\mathrm{Pb}$ no corpo de frutificação desses cogumelos é significativamente reduzida, indicando que os mecanismos de absorção e bioacumulação de metais podem variar de acordo com a espécie de cogumelo. ${ }^{132,133} \mathrm{O}$ acúmulo de $\mathrm{Cd}, \mathrm{Hg}$ $\mathrm{e} \mathrm{Pb}$ nesses macrofungos pode ser alterado por fatores fúngicos e ambientais. ${ }^{134}$ Arica et al. ${ }^{135}$ reportaram que os cogumelos Pleurotus sajur-caju foram capazes de remover $81 \%$ dos íons de $\mathrm{Hg}$ (II) de amostras sintéticas de águas residuais. ${ }^{135}$

Fatores fúngicos (espécie de cogumelo, morfologia do corpo de frutificação, fases de desenvolvimento, idade do micélio, composição bioquímica e intervalo entre as frutificações) e fatores ambientais (quantidade de matéria orgânica, pH e concentração dos metais no 
solo) podem alterar a bioacumulação dos metais nos cogumelos. ${ }^{134}$ Sendo assim, é fundamental destacar a importância de avaliar a composição do substrato de cultivo em processos de enriquecimento de organismos bioacumuladores, uma vez que além de elementos essenciais utilizados para suplementação, alguns elementos tóxicos presentes no substrato de cultivo também podem ser bioacumulados nos cogumelos.

\section{Enriquecimento com Fe e Se: brotos de feijão azuki (Vigna angulares), shimeji branco (Pleurotus ostreatus) e o cogumelo salmão ou "hiratake salmon" (Pleurotus djamor)}

Cerca de 21 elementos são considerados essenciais para o bom funcionamento do organismo e podem ser divididos em dois grupos: macro e microelementos, os quais desempenham funções essenciais à saúde, entre elas a regulação de processos enzimáticos, manutenção do equilíbrio osmótico, facilitação da transferência de substâncias pelas membranas celulares e estimulação nervosa-muscular. ${ }^{136} \mathrm{~A}$ quantidade adequada de elementos essenciais requeridas pelos seres humanos está relacionada à DRI. Regulamentações determinadas pela Food and Drug Administration ${ }^{137}$ apresentam valores de DRI para alguns elementos essenciais, entre eles: $\mathrm{Ca}(1000 \mathrm{mg}), \mathrm{Cu}(2 \mathrm{mg})$, Fe $(18 \mathrm{mg}), \mathrm{Mg}(400 \mathrm{mg}), \mathrm{P}(1000 \mathrm{mg}), \mathrm{Se}(55 \mu \mathrm{g})$ e $\mathrm{Zn}(15 \mathrm{mg})$ considerando um indivíduo adulto, $70 \mathrm{~kg}$ a partir de 31 anos. ${ }^{137}$

Um dos grandes problemas de saúde pública em países em desenvolvimento é a deficiência de $\mathrm{Fe}$ e $\mathrm{Se}^{138}$, de acordo com a tabela de composição química dos alimentos adotada pela UNIFESP o feijão azuki possui $49,8 \mu \mathrm{g} \mathrm{g}^{-1}$ de Fe e a concentração de selênio não é apresentada. ${ }^{139}$ Feijões contribuem como as maiores fontes vegetais de Fe total, porém, estudos evidenciam que essa leguminosa possui baixa concentração de espécies de Fe disponível para absorção, ${ }^{140}$ sendo que o consumo desse alimento como uma fonte de Fe com potencial para suprir deficiências nutricionais, como a anemia, não é uma realidade. Em um estudo sobre a interação do metabolismo de $\mathrm{Fe}$ e $\mathrm{Cu}$ em ratos verificou-se que existe influência do $\mathrm{Cu}$ no aumento de hemoglobina, hematócrito e Fe no sangue de ratos anêmicos, sugerindo uma interação do $\mathrm{Cu}$ com o metabolismo do Fe. ${ }^{141}$

O Brasil mostra índices crescentes de prevalência de anemia ferropriva, com níveis que chegam a $70 \%$ em algumas regiões, ${ }^{142}$ a nível mundial estima-se que quase $40 \%$ da população apresenta carência de Fe ou níveis baixos de hemoglobina, estabelecendo uma situação de risco que inclui indivíduos de todas as classes sociais, especialmente o grupo materno-infantil: lactentes, pré-escolares, escolares, gestantes e nutrizes. ${ }^{143}$

Há duas formas principais de espécies de Fe: ferro heme proveniente em sua maior parte de fontes animais, enquanto o ferro não-heme é proveniente de fontes vegetais. O ferro heme é constituinte da hemoglobina, da mioglobina e compõe enzimas. Como constituinte da hemoglobina, o Fe é requerido para o transporte de gás oxigênio e dióxido de carbono estando assim, diretamente envolvido no processo de respiração celular. O ferro não-heme constitui as espécies inorgânicas de $\mathrm{Fe}$, metaflavoproteínas implicadas no metabolismo oxidativo e proteínas ferro-enxofre que são proteínas contendo átomos de Fe e que não estão localizados dentro de um grupo heme, mas ligados a átomos de enxofre inorgânico como parte de um centro ferro-enxofre. ${ }^{144}$

No que diz respeito a absorção de diferentes espécies de Fe no organismo humano, o Fe heme representa de 5 a $10 \%$ do Fe dietético, porém sua absorção pode chegar a $25 \%$ quando comparada a apenas $5 \%$ do Fe não-heme. ${ }^{145}$ Dentre as espécies inorgânicas de Fe, o íon $\mathrm{Fe}$ (II) é solúvel em condições fisiológicas e difunde-se livremente através das membranas, enquanto que o Fe(III) é menos absorvido e é mais propenso à hidrólise em sistemas biológicos. Quando há espécies de Fe(III), sua absorção em quelatos de células eucarióticas envolve dissociação do complexo seguido pela redução e transporte de $\mathrm{Fe}(\mathrm{II}) .{ }^{136}$ Nos alimentos de origem vegetal, o Fe não-heme está presente como espécies inorgânicas de $\mathrm{Fe}(\mathrm{II})$ ou Fe(III), onde a biodisponibilidade do $\mathrm{Fe}(\mathrm{II})$ é maior do que a de $\mathrm{Fe}(\mathrm{III})$, pois a última espécie de Fe é menos solúvel no lúmen intestinal. ${ }^{146}$

Embora a deficiência de Se não seja tão estudada como aquela do $\mathrm{Fe}$, esse também constitui um elemento de grande importância nutricional. O Se é um elemento essencial e proporciona diversos benefícios a saúde e nutrição humana, além de apresentar propriedades anticarcinogênicas para alguns tipos de câncer. ${ }^{147,148}$ Entretanto, as faixas para a sua ingestão: deficiente $\left(<40 \mu \mathrm{g} \mathrm{dia}^{-1}\right)$, apropriado (50$75 \mu \mathrm{g} \mathrm{dia}^{-1}$, dependendo a idade, sexo e histórico médico) e tóxico (> $\left.600 \mu \mathrm{g} \mathrm{dia}^{-1}\right)$ são estreitas. ${ }^{74}$ Estudos indicaram que a ingestão diária de 100 - $200 \mu \mathrm{g} \mathrm{dia}{ }^{-1}$ de Se é capaz de reduzir o risco de câncer em humanos. ${ }^{149}$ A deficiência de Se no organismo está relacionada com o aumento do colesterol no plasma sanguíneo, disfunções do fígado e a doença de Kesham, que atingem mais de 10 milhões de chineses. ${ }^{150}$

\section{Brotos de feijão azuki (Vigna angularis)}

O gênero Vigna compreende cerca de 160 espécies, das quais somente sete são cultivadas. O feijão adzuki ou azuki (Vigna angularis) encontra-se entre as 12 leguminosas cultivadas mais importantes no mundo, apresenta grãos pequenos, de coloração avermelhada com pequeno hilo branco, produzido e consumido principalmente na Ásia. ${ }^{151}$ O feijão azuki possui cerca de $50 \%$ de amido, $25 \%$ de proteína, ${ }^{152,153}$ sendo uma das espécies de feijão mais utilizada e recomendada para o cultivo e consumo de brotos. ${ }^{154}$ Porém, apesar da destacada importância no cultivo mundial de leguminosas, estudos sobre a composição química em grãos e brotos de feijão azuki são escassos.

É crescente a busca por alternativas que se adaptem ao novo conceito de alimentos saudáveis e livres de agrotóxicos que podem causar danos à saúde e ao meio ambiente. $\mathrm{O}$ consumo de alimentos germinados é um segmento que merece destaque na alimentação humana e está em franca expansão no Brasil, sendo uma técnica amplamente utilizada nos Estados Unidos, Europa e Ásia, a qual pode ser implantada inclusive no meio urbano. ${ }^{102}$ Denomina-se alimento germinado ou brotos quaisquer semente que é estimulada após contato com fatores externos como água, ar e calor, tendo como resultado o crescimento. Após o processo de germinação, as sementes irão formar o caule e as folhas, preenchendo-se pouco a pouco com clorofila, originando os brotos. ${ }^{155}$ Os brotos são alimentos altamente nutritivos, em cuja produção é rápida, cerca de 7 a 15 dias e pode ser realizada em qualquer época do ano, sem a necessidade de solo, fertilizantes, agrotóxicos e luz solar direta. ${ }^{151}$

O processo de germinação pode levar a alterações nutricionais e a redução significativa de antinutrientes, tais como inibidores de enzimas, tornando o consumo de alguns brotos seguro para a alimentação humana. ${ }^{156}$ Os grãos germinados são boas fontes de ácido ascórbico, riboflavina, colina, tiamina, tocoferóis e vitamina $\mathrm{B}_{5}$ (ácido pantotênico: ácido 3-[amino (2,4-di-hidroxi-3,3-dimetilbutanoil)] propanóico). ${ }^{157}$ Durante o processo de germinação, as enzimas presentes nos grãos, entre elas a fitase, são ativadas por hidratação e o ácido fítico é hidrolisado, consequentemente, ocorrem reduções nos teores de fitato e o aumento na biodisponibilidade elementar. ${ }^{158}$

Os brotos de feijão são servidos como vegetais básicos e utilizados em sopas e saladas em diversos países asiáticos. Adicionalmente, eles são apreciados pelo seu paladar e pelo valor nutritivo e medicinal. ${ }^{151}$ O feijão mungo (Vigna radiata), popularmente conhecido como "moyashi”, é a espécie mais utilizada para a produção de brotos no Brasil, seguida pelo feijão azuki (Vigna angularis), ${ }^{159}$ os quais são boas fontes de minerais, vitaminas, proteínas e apresentam baixo teor 
calórico. Sendo assim, quando presentes na dieta alimentar suprem eventuais deficiências nutricionais, além de ser possível enriquecer os brotos com elementos essenciais.

Nos trabalhos propostos por Oliveira et al..$^{11,44,45}$ os brotos de feijão azuki apresentaram cultivo rápido, aproximadamente 13 dias de cultivo. As sementes foram germinadas em meio enriquecido contendo sais de $\mathrm{Fe}\left(\mathrm{FeSO}_{4}\right.$ ou $\left.\mathrm{FeCl}_{3}\right)$, complexo de $\mathrm{Fe}$ (NaFe(III)-EDTA) ou sais de $\mathrm{Se}\left(\mathrm{Na}_{2} \mathrm{SeO}_{3}\right.$ ou $\left.\mathrm{Na}_{2} \mathrm{SeO}_{4}\right)$, desenvolvendo-se em condições de estresse abiótico, ou seja, condições extremas expostas pelo meio. Plantas sob condições de estresse abiótico são aquelas submetidas a altas concentrações elementares no solo de cultivo, condições de seca, solos com alta salinidade ou constituintes inorgânicos, presença de metais pesados, temperaturas extremas, entre outros ${ }^{160}$ sendo a adição de elementos o principal fator que altera as características da planta ao ser cultivada no meio enriquecido.

Para o enriquecimento com Fe, mesmo em altas concentrações desse elemento no substrato de cultivo, observou-se que independente do sal de $\mathrm{Fe}\left(\mathrm{FeCl}_{3}\right.$ ou $\left.\mathrm{FeSO}_{4}\right)$ usado, houve uma baixa translocação desse analito até o caule, acumulando-se principalmente nas raízes. $\mathrm{O}$ transporte do Fe ocorre pelo xilema, via corrente transpiratória, predominante na forma de quelato do ácido cítrico $\left(\mathrm{C}_{6} \mathrm{H}_{5} \mathrm{O}_{7} \mathrm{Fe}\right)$. O Fe possui mobilidade consideravelmente reduzida no xilema, sendo incorporado aos cloroplastos. A translocação de Fe entre órgãos e tecidos envolve diversos quelantes e redutores. ${ }^{161}$ Adicionalmente, a absorção de Fe do substrato de cultivo em plantas envolve a redução de Fe(III) e proteínas de membranas responsáveis pelo transporte de íons hidrônio $\left(\mathrm{H}^{+}\right)$, os quais são induzidos pela deficiência de $\mathrm{Fe}$. O Fe é pouco redistribuído na planta e para que o íon absorvido pela raiz possa atingir a parte aérea, deve ocorrer o transporte radial e o de longa distância. ${ }^{162}$

Estudos que avaliam a absorção e translocação de $\mathrm{Fe}$ a partir de $\mathrm{FeSO}_{4}$ ou $\mathrm{FeCl}_{3}$, em diferentes partes de brotos, são escassos. Wei et al. ${ }^{33}$ estudaram a eficiência da utilização de $\mathrm{FeSO}_{4}$ no processo de germinação e fortificação em arroz, porém, não houve enriquecimento do substrato de cultivo. As sementes foram imersas por um período de $10 \mathrm{~h}$ em uma solução de Fe e o enriquecimento foi avaliado após o período de germinação de 24 h. Verificou-se um aumento significativo na concentração de Fe total, sendo 10 vezes maior em relação ao grupo controle, ao deixar os grãos imersos em solução de $\mathrm{FeSO}_{4}\left(2 \mathrm{~g} \mathrm{~L}^{-1}\right)$. ${ }^{33}$

No enriquecimento adicionando Fe(III)-EDTA ao substrato de cultivo, a concentração de Fe na raiz não sofreu significativa alteração, indicando um menor acúmulo na parte inferior da planta e uma possível facilidade de translocação de Fe no tecido vegetal. O EDTA é um agente complexante de hexacoordenação e pode complexar-se com íons metálicos através de quatro grupos carboxilato e dois grupamentos amina. A eficácia do EDTA como quelante para um determinado metal depende da sua constante de estabilidade $\left(\mathrm{K}_{\mathrm{est}}\right)$ com o metal, sendo que entre os metais nutricionalmente importantes, o complexo com $\mathrm{Fe}(\mathrm{III})$ apresenta a maior $\mathrm{K}_{\text {est }}(25,1) .{ }^{163}$ Sendo assim, a maior estabilidade da molécula de Fe(III)-EDTA e a facilidade dessa espécie em atravessar a raiz da planta sem complexar-se a componentes orgânicos, tais como oxalatos, presentes na raiz favorece a translocação desse elemento para a parte aérea (caule).

Considerando o broto enriquecido com Fe(III)-EDTA, o consumo de $115 \mathrm{~g}$ (massa seca) de brotos cultivados em meio enriquecido com $3000 \mu \mathrm{g}$ de $\mathrm{Fe}$ (Fe(III)-EDTA) atinge a DRI de Fe $(18 \mathrm{mg}) .{ }^{11}$ É importante destacar que além do procedimento de enriquecimento com $\mathrm{Fe}$ aumentar a concentração total de $\mathrm{Fe}$, a associação de $\mathrm{Fe}$ às proteínas também foi favorecida, uma vez que 55 e $63 \%$ do Fe total estava associado à proteínas nos brotos de feijão do grupo controle e enriquecido, respectivamente. Os principais aminoácidos constituintes de albuminas, globulinas e glutelínas são ricos em enxofre e grupos carregados, tais como metionina, cisteína, ácido glutâmico, arginina, ácido aspártico e lisina, os quais o Fe apresenta alta afinidade. ${ }^{164}$

Outras espécies de Fe foram analisadas: Fe solúvel, Fe não associado a macromoléculas (incluindo o Fe inorgânico) e Fe não associado a macromoléculas e não inorgânico, como por exemplo, $\mathrm{Fe}$ associado às fibras solúveis. O enriquecimento com Fe(III)-EDTA pôde auxiliar no aumento das espécies de Fe disponíveis para absorção, o qual foi capaz de aumentar em 75, 50 e $145 \%$ a concentração de Fe total, solúvel e inorgânico, respectivamente. ${ }^{11}$

Para o enriquecimento com Se, Se(VI) mostrou-se também mais eficiente para a translocação na planta, no qual a concentração de Se no caule aumentou 9 vezes em relação ao caule do broto cultivado em algodão hidrófilo fortificado com solução de Se(IV).${ }^{45}$ Este resultado é consistente com os relatados para brócolis e outras plantas, onde o fornecimento de $\mathrm{Se}(\mathrm{VI})$ proporcionou maior translocação e elevou o acúmulo de Se na parte aérea de plantas, para a mesma concentração de Se aplicada ao substrato de cultivo. ${ }^{21,119}$ Considerando os brotos enriquecidos com Se e o valor de ingestão diária recomendada para um indivíduo saudável (adulto; $70 \mathrm{~kg}$; até 70 anos), a ingestão de uma massa seca de 21,4 $\mathrm{g}(\mathrm{Se}(\mathrm{IV}))$ e $2,4 \mathrm{~g}(\mathrm{Se}(\mathrm{VI}))$ atinge a faixa de 100-200 $\mu \mathrm{g} \mathrm{dia}^{-1}$ de Se e pode ser capaz de reduzir o risco de alguns tipos de câncer em humanos. ${ }^{74,147-149}$

A mobilidade, biodisponibilidade e toxicidade de Se em plantas é diferente, devido às características genéticas e metabólicas das plantas, assim com possíveis interações do Se com diferentes meios de cultivo, e, ainda, diferenças no mecanismo de absorção e translocação de $\mathrm{Se}(\mathrm{IV})$ e $\mathrm{Se}(\mathrm{VI})$ no xilema. ${ }^{57,165,166} \mathrm{O} \mathrm{Se}(\mathrm{VI})$ apresenta disponibilidade e mobilidade maiores quando comparado ao Se(IV) e, por razões ainda pouco conhecidas, a biodisponibilidade de $\mathrm{Se}$ para plantas pode variar consideravelmente.

Portanto, a translocação de $\mathrm{Se}$ da raiz até o broto também é altamente dependente da espécie química adicionada ao substrato de cultivo e seguem mecanismos metabólicos distintos. Um estudo realizado por Zayed et al. ${ }^{167}$ indicou que o $\mathrm{Se}(\mathrm{VI})$ foi mais facilmente translocado quando comparado ao $\mathrm{Se}(\mathrm{IV})$ ou outras espécies orgânicas, tais como SeMet. O Se(IV) que foi absorvido de forma passiva e estocado na raiz, possui baixa mobilidade e foi rapidamente convertido em formas orgânicas de Se que ficaram retidas nas raízes, as quais apresentam baixa mobilidade no xilema e foram incorporadas em proteínas em substituição ao $\mathrm{S}$, tendo, portanto, maior toxicidade quando comparado ao $\mathrm{Se}(\mathrm{VI}){ }^{44,111,168,169} \mathrm{O} \mathrm{Se}(\mathrm{VI})$, não foi tão facilmente convertido em formas orgânicas, foi altamente móvel no xilema e reduzido a Se(IV) no metabolismo, envolvendo glutationa reduzida no processo, e absorvido de forma ativa pelas plantas, competindo com a absorção de sulfato na via metabólica. ${ }^{169}$

Foi encontrado Se associado à proteínas, correspondendo a $54 \%$ nos brotos de feijão enriquecidos com Se(IV) e $19 \%$ com Se(VI). O $\mathrm{Se}(\mathrm{IV})$ foi absorvido de forma passiva e rapidamente convertido em formas orgânicas de Se, que foram incorporadas em proteínas em substituição ao $\mathrm{S}$, apresentando maior toxicidade para a planta quando comparado ao Se(VI). Por outro lado, o Se(VI) não foi tão facilmente convertido em formas orgânicas, sendo altamente móvel no xilema. ${ }^{44}$

As espécies orgânicas hidrofóbicas de Se foram determinadas após o procedimento de extração por ponto nuvem (CPE, do inglês, cloud point extraction) na fase rica em surfactante na ausência de ditizona $\left(\mathrm{H}_{2} \mathrm{DZ}, \mathrm{C}_{13} \mathrm{H}_{12} \mathrm{~N}_{4} \mathrm{~S}\right) .{ }^{44} \mathrm{~A}$ fase pobre em surfactante, contendo as espécies orgânicas hidrofílicas de Se de baixo peso molecular e as espécies inorgânicas, obtida após a extração das espécies orgânicas hidrofóbicas, foi submetida a um segundo procedimento de CPE na presença de $\mathrm{H}_{2} \mathrm{DZ}$, resultando na determinação de $\mathrm{Se}(\mathrm{IV})$ na fase rica em surfactante, pois a ditizona complexa apenas com Se(IV) formando uma espécie hidrofóbica. A determinação da concentração total de espécies de Se inorgânico foi realizada repetindo o procedimento 
de CPE, porém, a fase pobre em surfactante obtida foi submetida à etapa de redução do $\mathrm{Se}(\mathrm{VI})$, utilizando $\mathrm{HCl}$. Posteriormente, o procedimento de $\mathrm{CPE}$ com adição de $\mathrm{H}_{2} \mathrm{DZ}$ foi utilizado, obtendo-se a concentração total do Se inorgânico. Subtraindo a concentração de $\mathrm{Se}(\mathrm{IV})$ da concentração de Se inorgânico total foi possível determinar a concentração das espécies de $\mathrm{Se}(\mathrm{VI})$. As espécies orgânicas hidrofílicas de Se foram quantificadas subtraindo a concentração total de Se inorgânico da concentração de Se na fase pobre em surfactante obtida após o procedimento de CPE na ausência de $\mathrm{H}_{2}$ DZ. ${ }^{44}$

Um enriquecimento de alimentos bem sucedido não está apenas relacionado ao aumento na concentração total de um determinado elemento, mas também a formação de espécies bioacessíveis e biodisponíveis. De acordo com a literatura, sabe-se que espécies orgânicas de Se são consideradas mais biodisponíveis e apresentam menor toxicidade, enquanto o Se(IV) é mais tóxico que o Se(VI). ${ }^{170,171}$ Considerando o procedimento de enriquecimento proposto, os estudos de especiação química mostraram que as espécies orgânicas, principalmente as espécies hidrofílicas, são os constituintes majoritários no caule de brotos enriquecidos, correspondendo a 93\% da concentração total. Por outro lado, as espécies inorgânicas de Se correspondem a $5,4 \%$ da concentração total de Se, no qual o Se(IV) está presente em uma porcentagem menor $(1,4 \%)$ quando comparado ao Se(VI) $(4,0 \%)$. Sendo as espécies de Se orgânico mais biodisponíveis que as espécies inorgânicas e considerando a especiação química do Se, o consumo de aproximadamente $2 \mathrm{~g}$ do caule dos brotos de feijão azuki cultivado em meio enriquecido com $250 \mu \mathrm{g}$ de $\mathrm{Se}(\mathrm{VI})$ ainda é adequado para atingir o consumo máximo de $200 \mu \mathrm{g} \mathrm{dia}^{-1} \mathrm{de} \mathrm{Se}^{44}$

Ensaios in vitro foram realizados para a avaliação da bioacessibilidade de elementos essenciais em brotos (caule) de feijão azuki enriquecidos com $\mathrm{Fe}$ ou Se. Foi verificado que as espécies de Se formadas na parte comestível da planta (caule) após o procedimento de cultivo em meio enriquecido com $\mathrm{Se}(\mathrm{IV})$ ou $\mathrm{Se}(\mathrm{VI})$ são $100 \%$ bioacessíveis. O enriquecimento com Se(IV) não alterou significativamente a porcentagem bioacessível de $\mathrm{Ca}, \mathrm{Cu}, \mathrm{Mg}, \mathrm{P}$ e S, e o $\mathrm{Se}(\mathrm{VI})$ não alterou a bioacessibilidade de $\mathrm{Ca}, \mathrm{Cu}, \mathrm{P}, \mathrm{Mg}, \mathrm{P}, \mathrm{S}$ e $\mathrm{Zn}$. Adicionalmente, verificou-se que o enriquecimento com Fe(III)EDTA aumentou em $4 \%$ a porcentagem de Fe bioacessível, indicando a eficácia no uso do complexo de Fe para o enriquecimento, no qual a concentração total de Fe na parte comestível da planta aumentou, assim como a concentração de Fe solúvel, favorecendo a bioacessibilidade elementar na digestão gastrointestinal. ${ }^{11,45}$

\section{Cogumelos comestíveis: shimeji branco (Pleurotus ostreatus) e salmão ou "hiratake salmon" (Pleurotus djamor)}

O shimeji branco (Pleurotus ostreatus) é um dos cogumelos mais difundidos no mundo, comumente consumidos frescos ou desidratados, fonte de lisina e vitamina B $1 .{ }^{172} \mathrm{O}$ cogumelo salmão ou "hiratake salmon" (Pleurotus djamor) é uma espécie exótica de coloração rosa e textura fibrosa, consumido cru em pequenas quantidades, marinado com temperos, adornando saladas ou pratos com frutos do mar, apresenta alto potencial antioxidante e quando presentes na alimentação suprem eventuais deficiências nutricionais. ${ }^{172}$

Oliveira et al. ${ }^{12,84}$ adicionaram diferentes concentrações de Se(IV) ao substrato (bagaço de cana-de-açúcar, farelo de arroz, farelo de trigo, óxido de cálcio) inoculado com sementes de cogumelo salmão ou shimeji branco. Após o primeiro período de frutificação, aproximadamente 13 dias, verificou-se que a adição de Se não alterou significativamente o crescimento micelial do substrato e a forma do corpo de frutificação dos cogumelos, quando comparados ao grupo controle (Figura 2). Por outro lado, no shimeji branco cultivado em substrato enriquecido com 12,8 $\mu \mathrm{g} \mathrm{g}^{-1}$ de Se formaram-se corpos de frutificação com superfícies dos estipes e chapéus aparentemente mais secos e rígidos (Figura 2). ${ }^{84}$

Os resultados das características morfológica do cogumelo salmão avaliadas foram concordantes com aqueles observados por

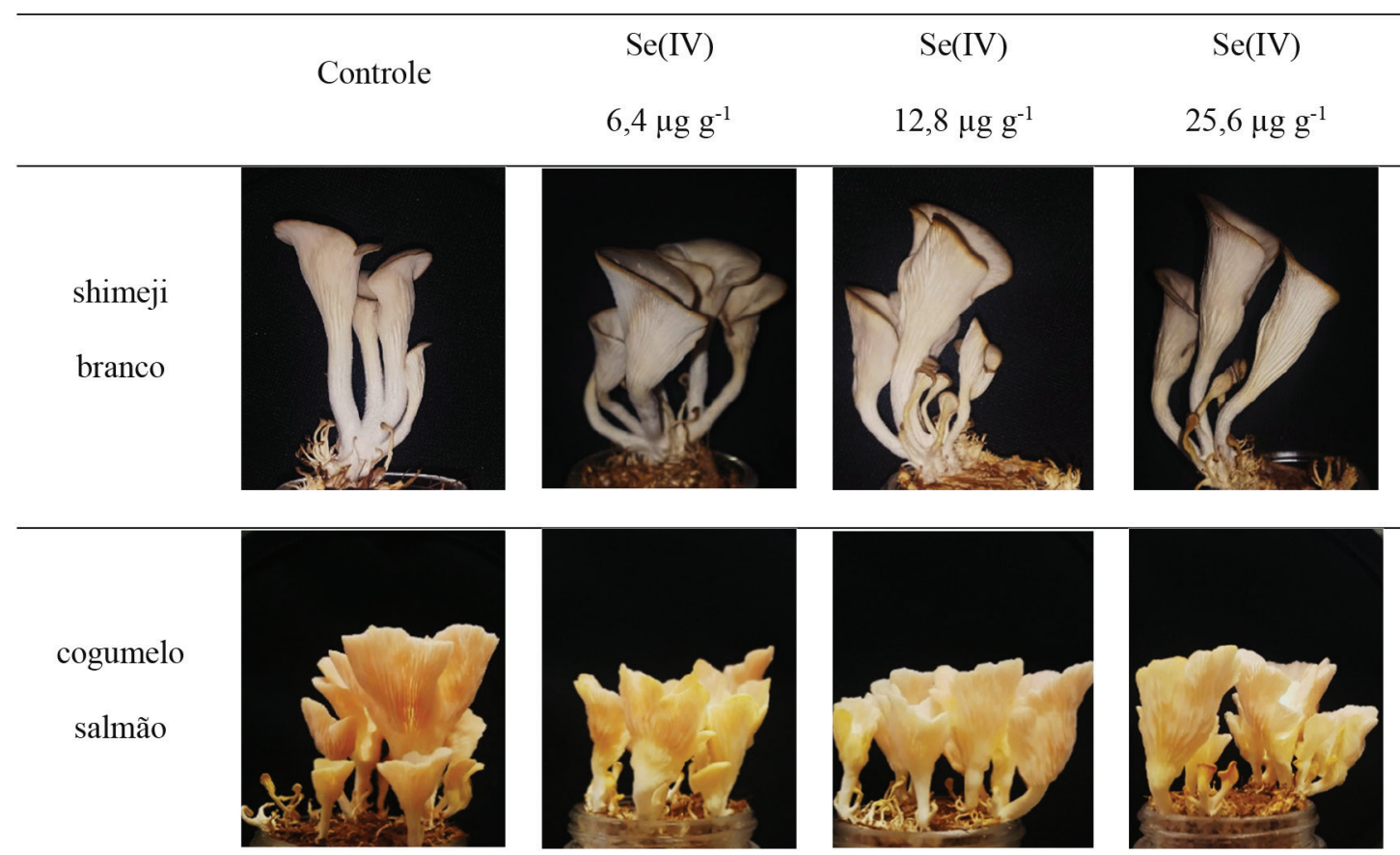

Figura 2. Cogumelo salmão (Pleurotus djamor) e shimeji branco (Pleurotus ostreatus) cultivados em $20 \mathrm{~g}$ de em substrato orgânico a base de bagaço de cana-de-açúcar composto por $5 \%\left(\mathrm{~m} \mathrm{~m}^{-1}\right)$ de farelo de arroz, $5 \%\left(\mathrm{~m} \mathrm{~m}^{-1}\right)$ de farelo de trigo e $4 \%\left(\mathrm{~m} \mathrm{~m}^{-1}\right)$ de CaO inoculado com sementes dos fungos, sendo o grupo controle cultivado com adição de água desionizada ao substrato inoculado e os grupo enriquecidos com Se(IV) a partir da adição de 5 mL de solução aquosa de $\mathrm{Na}_{2} \mathrm{SeO}_{3}$ com concentrações variáveis de forma a obter-se 6,4 $\mu \mathrm{g} \mathrm{g}^{-1}, 12,8 \mu \mathrm{g} \mathrm{g}^{-1}$ ou 25,6 $\mu \mathrm{g} \mathrm{g}^{-1}$ de Se(IV) adicionado em função da massa de $20 \mathrm{~g}$ do substrato inoculado 
Nunes et al. ${ }^{173}$ para cogumelos Lentinula edodes, os quais não apresentaram diferenças significativas na forma dos corpos de frutificação e comprimento dos estipes dos cogumelos enriquecidos com Se. ${ }^{173}$ Enquanto o efeito do enriquecimento nas características do corpo de frutificação do shimeji branco foi concordante com aqueles observados por Silva et al., ${ }^{9}$ no qual houveram alterações no crescimento micelial em cogumelos Pleurotus ostreatus quando cultivados em substratos com concentração de Se superior a $12,8 \mu \mathrm{g} \mathrm{g}^{-1}$, originando cogumelos de estipes maiores e chapéus menores com curvaturas menos definidas. ${ }^{9}$

As diferentes espécies de cogumelos foram capazes de absorver Se quando Se(IV) foi adicionado ao substrato, no qual o aumento da concentração de Se(IV) adicionado ao substrato inoculado favoreceu o aumento da concentração de Se no $1^{\circ}$ ciclo de frutificação. A ingestão diária de 2,5 g (massa seca) de ambas as espécies de cogumelos cultivados em meio contendo $25,6 \mu \mathrm{g} \mathrm{g}^{-1}$ de Se(IV) ultrapassa a DRI para um indivíduo saudável e atinge a faixa de ingestão de Se (100 a $\left.200 \mu \mathrm{g} \mathrm{dia}^{-1}\right)$, podendo reduzir o risco de alguns tipos de câncer. ${ }^{84}$

O efeito da adição de $\mathrm{Se}(\mathrm{IV})$ e $\mathrm{Se}(\mathrm{VI})$ ao substrato inoculado das diferentes espécies de cogumelos foi avaliado inicialmente através das características morfológicas dos corpos de frutificação formados nas diferentes espécies de cogumelos após 13 dias (cogumelo salmão) e 14 dias (shimeji branco) de cultivo do primeiro ciclo de frutificação (Figura 3). Apesar de serem verificadas alterações morfológicas nos cogumelos cultivados em meio suplementado com $\mathrm{Se}(\mathrm{VI})$, sendo formados cogumelos com a curvatura do chapéu pouco definida, os maiores efeitos de toxicidade no que diz respeito às características morfológicas visuais dos corpos de frutificação formados ocorreram no substrato de cultivo com adição de Se(IV), obtendo cogumelos com estipes menores e mais alongados para o shimeji branco. O enriquecimento com Se também alterou as características morfológicas dos cogumelos salmão, principalmente no cultivo com adição de $\mathrm{Se}(\mathrm{IV})$, produzindo cogumelos com coloração opaca e formação de lâminas amareladas, além de corpos de frutificação menores quando comparados ao grupo controle..$^{84}$

Os resultados apresentados para massa total acumulada evidenciaram a maior capacidade de acúmulo de Se nos corpos de frutificação ao utilizar Se(VI) no enriquecimento do substrato de cultivo, aumentando $107 \%$ (shimeji branco) e $110 \%$ (cogumelo salmão) a massa total de Se acumulado, quando comparados ao enriquecimento com $\mathrm{Se}(\mathrm{IV})$. De acordo com os resultados obtidos verificou-se que o shimeji branco e o cogumelo salmão poderiam ser considerados fungos hiperacumuladores, devido à capacidade de absorção de Se maior que $100 \mathrm{mg} \mathrm{kg}^{-1}$ em massa seca. ${ }^{93}$ Porém, é importante destacar que a eficiência no enriquecimento de cogumelos com Se também depende da espécie de Se adicionada ao substrato. Ao serem consideradas as alterações das características morfológicas nos corpos de frutificação e a capacidade de bioacumular Se presente no substrato inoculado, a adição de $\mathrm{Se}(\mathrm{VI})$ ao substrato mostrou-se a melhor alternativa de enriquecimento com Se para ambas as espécies de cogumelos avaliadas, favorecendo a maior bioacumulação de Se com menores efeitos tóxicos. ${ }^{84}$

Após enriquecimento de cogumelos salmão e shimeji branco em meio contendo Se(IV), verificaram-se que em ambas as espécies de cogumelos, o Se está associado, principalmente, as albuminas e glutelínas nos cogumelos ${ }^{84}$ Os principais aminoácidos constituintes de albuminas, globulinas e glutelínas são ricos em enxofre e grupos carregados, tais como metionina, cisteína, ácido glutâmico, arginina, ácido aspártico e lisina, ${ }^{174}$ os quais o Se apresenta alta afinidade. ${ }^{175}$

$\mathrm{O}$ Se atua principalmente através de selenoproteínas, a maioria das quais são oxidorredutases envolvidas em diversas funções celulares, tais como as enzimas antioxidantes glutationa peroxidase $\mathrm{e}$ a tiredoxina redutase que melhoram a resposta imune e inibem os mecanismos de iniciação de câncer. ${ }^{176}$ Além disso, no que diz respeito a ação de Se contra células cancerígenas estudos evidenciam que a morte de células cancerígenas por diferentes compostos de Se está

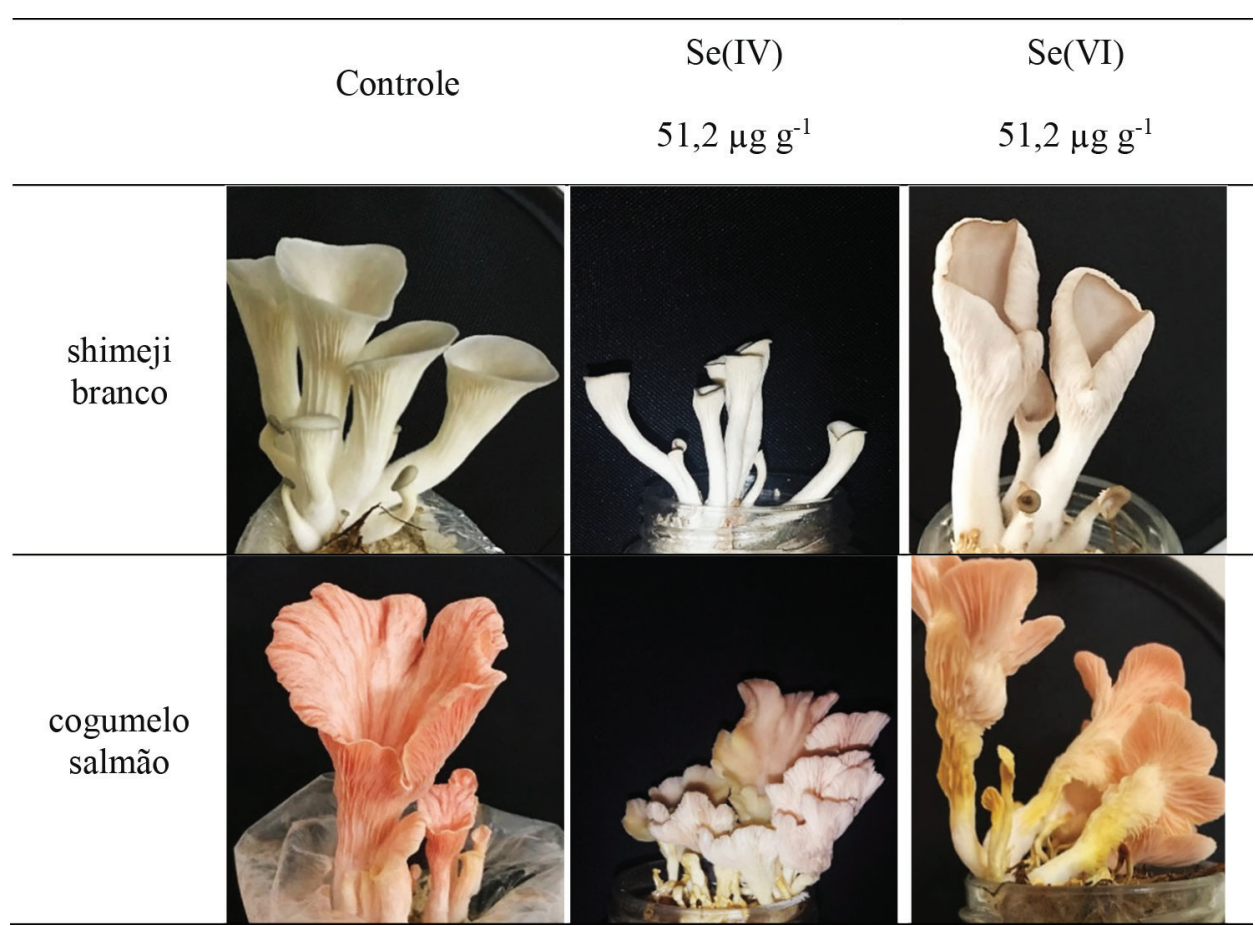

Figura 3. Morfologia do primeiro ciclo de frutificação dos cogumelos salmão (Pleurotus djamor) e shimeji branco (Pleurotus ostreatus) cultivados em $100 \mathrm{~g}$ de substrato orgânico a base de bagaço de cana-de-açúcar composto por $5 \%\left(\mathrm{~m} \mathrm{~m}^{-1}\right)$ de farelo de arroz, $5 \%\left(\mathrm{~m} \mathrm{~m}^{-1}\right)$ de farelo de trigo e $4 \%\left(\mathrm{~m} \mathrm{~m}^{-1}\right)$ de CaO inoculado com sementes dos fungos, sendo o grupo controle cultivado com adição de água desionizada ao substrato inoculado e os grupo enriquecidos com $\mathrm{Se}(\mathrm{IV})$ ou $\mathrm{Se}(\mathrm{IV})$ a partir da adição de $5 \mathrm{~mL}$ de solução aquosa de $\mathrm{Na}_{2} \mathrm{SeO}_{3}$ ou $\mathrm{Na}_{2} \mathrm{SeO}_{4}$ com concentrações variáveis de forma a obter-se $51,2 \mu g^{-1}$ de $\mathrm{Se}$ (IV) ou $\mathrm{Se}$ (VI) adicionado em função da massa de $100 \mathrm{~g}$ do substrato inoculado 
associada a diversos mecanismos que incluem modificações proteica, parada de crescimento celular e apoptose. ${ }^{177}$

Ensaios in vitro foram realizados para a avaliação da bioacessibilidade de elementos essenciais em shimeji branco e cogumelo salmão enriquecidos com Se(IV). Na parte comestível do cogumelo o Se apresentou-se como espécies solúveis (92 a 100\%) e bioacessíveis (100\%) para ambas as espécies de cogumelos. Os resultados de porcentagem de Se solúvel diferiram daqueles obtidos por Bhatia et al. ${ }^{87}$ para o enriquecimento de cogumelos Pleurotus florida, no qual apenas $75 \%$ do Se total foi solubilizado nas condições de digestão gastrointestinal. De acordo com estudos realizados por Serafin-Muñoz et al. ${ }^{91}$ em cogumelos, as espécies de Se insolúveis após a digestão gastrointestinal estavam associadas a polissacarídeos, no qual parte do Se nos cogumelos enriquecidos poderia estar associado a estruturas contendo quitina na parede celular. Portanto, além das condições de enriquecimento utilizadas, a bioacessibilidade do Se presente em diferentes espécies de cogumelos comestíveis também pode variar de acordo com a incorporação das espécies de Se em polissacarídeos. ${ }^{91}$

No que diz respeito ao efeito do enriquecimento com Se na bioacessibilidade de outros elementos essenciais e considerando a solubilidade dos elementos avaliados no fluido gastrointestinal, os resultados indicaram que as espécies de $\mathrm{Ca}$ e $\mathrm{Cu}$ não são bioacessíveis independentemente da espécie de cogumelo e condição de cultivo dos cogumelos. Adicionalmente, as espécies de $\mathrm{S}$ no shimeji branco também se apresentaram insolúveis e, consequentemente, não bioacessíveis. ${ }^{86}$

Para avaliar o efeito do enriquecimento com Se na solubilidade elementar, a porcentagem solúvel de cada elemento foi subtraída da porcentagem solúvel obtida no grupo controle. Sendo assim, verificaram-se que apesar do enriquecimento não alterar significativamente a concentração da maioria dos elementos avaliados, o enriquecimento com $\mathrm{Se}$ favoreceu o aumento da porcentagem solúvel de Fe (29 a 44\%), Mg (29 a 37\%), Mn (37 a 41\%), P (14 a 20\%), S (21 a 33\%) e Zn (28 a 35\%) no cogumelo salmão. Por outro lado, verificaram-se que o enriquecimento do shimeji branco diminuiu a porcentagem solúvel da maioria dos elementos em relação ao grupo controle, tais como o Fe (15 a 18\%), Mg (7 a 13\%), P (16 a 44\%) e Zn $(17$ a $26 \%) .{ }^{84}$

Para avaliar o efeito do enriquecimento com Se na bioacessibilidade elementar, a porcentagem bioacessível de cada elemento também foi subtraída da porcentagem bioacessível do grupo controle. Não ocorreram alterações significativas na porcentagem de K bioacessível em ambas as espécies de cogumelos enriquecidos quando comparados ao grupo controle. Além disso, verificou-se que o enriquecimento com Se promoveu um aumento na porcentagem bioacessível de $\mathrm{Fe}$ ( 7 a $11 \%), \operatorname{Mg}$ (12 a 13\%), P (4 a 6\%), S (7 a 12\%) e Zn (10 a 14\%) no cogumelo salmão, enquanto uma diminuição na porcentagem bioacessível de Fe (18 a 28\%) e P (7 a 13\%) foi verificada no shimeji branco. A bioacessibilidade de um elemento depende da composição da matriz e da forma química que o analito é encontrado. Assim como verificado para a concentração total, o enriquecimento com Se não alterou significativamente a porcentagem bioacessível de $\mathrm{Ca}, \mathrm{Cu}, \mathrm{Ke}$ Mn nas diferentes espécies de cogumelos, indicando que as espécies químicas desses elementos formadas após o enriquecimento foram similares ao grupo controle. ${ }^{84}$

Verificaram-se também que, além do Se, o Mn foi o único elemento que se mostrou $100 \%$ bioacessível em ambas as espécies de cogumelos após as diferentes condições de cultivo (grupo controle e enriquecido). Estudos realizados por Vitali et al. ${ }^{178}$ indicaram que existe um efeito antagônico entre a bioacessibilidade de $\mathrm{Mn}$ e a presença de polifenóis e fitato na matriz alimentar, enquanto um efeito sinérgico entre a bioacessibilidade de Mn e proteínas em alimentos foi observado. Possivelmente, a elevada porcentagem de
Mn bioacessível nas diferentes espécies de cogumelos cultivadas com adição de diferentes concentrações de Se deveu-se às elevadas concentrações de proteínas nos cogumelos comestíveis, tais como as proteínas do grupo das prolaminas e glutelínas. ${ }^{178}$

A avaliação da bioacessibilidade elementar indicou que os cogumelos enriquecidos são boas fontes de Se total e bioacessível. O enriquecimento com a maior concentração de Se avaliada $\left(25,6 \mu \mathrm{g} \mathrm{g}^{-1}\right)$ aumentou $11 \%$ a porcentagem de Se bioacessível no cogumelo salmão em relação ao grupo controle. ${ }^{84}$ Além disso, é importante destacar que o cogumelo salmão pode ser uma fonte valiosa de $\mathrm{Fe}$, uma vez que quando comparados a leguminosas comumente consumidas, tais como os feijões Phaseolus que são consideradas boas fontes vegetais de Fe total, o cogumelo salmão apresentou a concentração de $\mathrm{Fe}$ $35,1 \%$ maior quando comparado ao feijão preto. ${ }^{179}$

Uma alternativa promissora e talvez mais rápida para a avaliação do efeito do enriquecimento de cogumelos comestíveis com Se também foi avaliada, desenvolvendo métodos de imageamento químico de $\mathrm{Ca}, \mathrm{Mg}$ e $\mathrm{K}$ por espectrometria de emissao óptica com plasma induzido por laser (LIBS, do inglês laser-induced breakdown spectroscopy). Verificou-se que o enriquecimento com Se alterou significativamente a distribuição elementar no corpo de frutificação dos cogumelos comestíveis. ${ }^{12} \mathrm{Na}$ parte inferior dos cogumelos houve um acúmulo de Ca e um decréscimo nos valores de correlação numérica entre a distribuição de $\mathrm{Ke} \mathrm{Mg}$ foi verificado nos cogumelos Pleurotus djamor quando comparados ao grupo controle. Por outro lado, para os cogumelos Pleurotus ostreatus, apesar do enriquecimento com Se alterar as características morfológicas dos cogumelos, a distribuição de $\mathrm{K}$ e $\mathrm{Mg}$ não foram alteradas. ${ }^{12}$

\section{DESAFIOS NA PRODUÇÃO DE ALIMENTOS ENRIQUECIDOS}

O enriquecimento de alimentos é uma estratégia promissora para promover o aumento da qualidade nutricional e econômica de produtos de origem agrícola. Porém, alguns elementos essenciais, principalmente microelementos, apresentam baixa translocação e, consequentemente, acúmulo em partes inferiores de plantas e fungos comestíveis. Considerando esse obstáculo, estratégias de enriquecimento com diferentes espécies elementares adicionados ao solo, substrato ou soluções de cultivo podem ser mais eficientes para promover a absorção, translocação e acúmulo desse elemento em partes comestíveis dos alimentos, já que se adiciona as espécies potencialmente acessíveis à planta e ao fungo.

As estratégias de enriquecimento múltiplo são mais viáveis economicamente quando comparadas a procedimento que visam o aumento nos níveis de apenas um nutriente nos alimentos e são aplicados com sucesso para elevar a qualidade de vida principalmente das populações em países em desenvolvimento. Apesar dos métodos de adição múltipla de elementos essenciais ao solo ou substrato de cultivo serem promissores e largamente utilizados na produção de produtos agrícolas enriquecidos, a translocação de alguns micronutrientes das raízes para as partes comestíveis das plantas através do xilema também é um desafio para a aplicação de estratégias de enriquecimento múltiplo bem sucedidas, uma vez que, podem ocorrer interações que alteram a absorção de um elemento na presença de outro elemento assim como alterações no metabolismo da planta que modificam significativamente a taxa de translocação elementar.

Para o sucesso do enriquecimento elementar é preciso conhecer as espécies elementares capazes de serem absorvidas, translocadas e acumuladas nas partes comestíveis das plantas e fungos. Porém, deve ir além disso, já que a determinação das espécies elementares formadas após o enriquecimento é de suma importância, uma vez que, é necessário avaliar se esses alimentos fortificados apresentam as 
mesmas características químicas daquelas formadas quando o alimento é cultivado em condições naturais. Portanto, a especiação química deve ser uma das principais aliadas dos processos de enriquecimento por meio de cultivo. Adicionalmente, estudos de bioacessibilidade e biodisponibilidade também devem ser feitos, viabilizando o consumo desses alimentos enriquecidos.

Considerando os trabalhos de cultivo em meio enriquecido para plantas comestíveis, é possível notar que os estudos estão voltados à translocação e acúmulo dos elementos. No entanto, é de suma importância aprofundar a caracterização química dos alimentos enriquecidos, principalmente com relação às espécies elementares formadas, sempre comparando com o alimento que foi cultivado em condições normais. Sendo assim, estudos de especiação química elementar, e complementados com estudos de bioacessibilidade e biodisponibilidade, são imperativos.

Para fungos, principalmente cogumelos comestíveis e medicinais, os estudos de enriquecimento com elementos essenciais e tóxicos estão mais aprofundados, até mesmo com relação à composição química das espécies elementares. Acreditamos que há diversas espécies de cogumelos que carecem de estudos de enriquecimento, bem como de especiação química. Além disso, estudos de bioacessibilidade e biodisponibilidade ainda merecem maior atenção da comunidade científica com relação aos cogumelos enriquecidos.

\section{CONSIDERAÇÕES FINAIS}

Esta revisão mostra que o desenvolvimento e aprimoramento de procedimentos de enriquecimento elementar de produtos de origem agrícola fornecem alternativas para a produção de alimentos de alto valor nutricional e econômico, os quais são capazes de suprir deficiências nutricionais, contribuindo inclusive na disseminação de uma alimentação saudável e, até mesmo, funcional.

A eficiência do enriquecimento elementar de plantas e fungos depende da espécie química dos elementos adicionados ao solo ou substrato, condições de cultivo, fisiologia das plantas ou fungos, absorção e translocação, relações antagônicas e, principalmente, o potencial de biotransformação de espécies presentes no solo ou substrato de cultivo em espécies altamente biodisponíveis na parte comestível do produto agrícola.

O enriquecimento de organismos bioacumuladores também merece destaque e origina estratégias eficazes para a produção de alimentos agrícolas enriquecidos. Porém, apesar de organismos bioacumuladores apresentarem elevado potencial para acumular elementos essenciais, esses organismos podem acumular elementos tóxicos presentes no substrato de cultivo, sendo necessário o controle dos níveis desses metais para produção e comercialização desses produtos.

Estudos da distribuição, competição e forma química em que os elementos são encontrados em um alimento enriquecido são importantes e podem resultar em informações a respeito da absorção, biodisponibilidade, benefícios e, eventualmente, riscos à saúde causados pela ingestão dos mesmos. Nesse sentido, estudos de especiação química são de suma importância, pois permitem identificar e/ou determinar as formas químicas em que o elemento é encontrado na matriz. A determinação das diferentes formas químicas dos elementos pode resultar em informações sobre a absorção, bioacessibilidade, e até mesmo a biodisponibilidade, além de serem capazes de inferir sobre a toxicidade e essencialidade dos elementos, promovendo conhecimentos capazes de auxiliar na evolução e aprimoramento de informações a respeito da utilização consciente de alimentos funcionais enriquecidos, uma vez que as diferentes espécies químicas geradas serão capazes de agir diferentemente no sentido de modular os processos metabólicos, prevenindo o aparecimento precoce de doenças degenerativas, levando ao aumento da longevidade.

\section{AGRADECIMENTOS}

Aline Pereira de Oliveira agradece a bolsa de mestrado e doutorado da Fundação de Amparo à Pesquisa do Estado de São Paulo/ FAPESP (Proc. 2015/01128-6, 2017/05009-7 e 2019/00663-6) e Juliana Naozuka agradece o apoio financeiro da FAPESP (Proc. 2015/15510-0 e 2018/00663-6), CNPq e CAPES.

\section{REFERÊNCIAS}

1. Black, R. E.; Allen, L. H.; Bhutta, Z. A.; Caulfield, L. E.; De Onis, M.; Ezzati, M.; Lancet 2008, 371, 243.

2. Ahmed, A.; Anjum, F. M.; Rehman, S. U.; Randhawa, M. A.; Farooq, U.; Plant Foods Hum. Nutr. 2008, 63, 7.

3. http://portal.anvisa.gov.br/documents/33916/394219/Portaria_SVS_ MS_31_de_13_de_janeiro_de_1998.pdf/178c46b7-3676-422b-8f02048eb796c16d, acessada em Janeiro de 2020.

4. Rebellato, A. P.; Pacheco, B. C.; Prado, J. P.; Pallone, J. A. L.; Food Res. Int. 2015, 77, 391.

5. Sabatier, M.; Egli, I.; Hurrell, R.; Hoppler, M.; Gysler, C.; Georgeon, S.; Zeder, C.; Eur. J. Nutr. 2017, 56, 1551.

6. Diego, Q. K.; Barberá, R.; Cilla, A.; Crit. Rev. Food Sci. Nutr. 2017, 57, 2028.

7. Hirata, A. M.; Braga, J. A. P.; Souza Vitalle, M. S.; Amancio, O. M. S.; Nutrire 2017, 42, 11.

8. Hu, Q.; Xu, J.; Pang, G.; J. Agric. Food Chem. 2003, 51, 3379.

9. da Silva, M. C.; Naozuka, J.; da Luz, J. M. R.; de Assunção, L. S.; Oliveira, P. V.; Vanetti, M. C.; Kasuya, M. C. Food Chem. 2012, 131, 558.

10. Naozuka, J.; Nutri. Food Sci. Int. 2018, 4, 1.

11. Oliveira, A. P.; Naozuka, J.; J Braz. Chem. Soc. 2017 28, 1937.

12. Oliveira, A. P.; de Oliveira Leme, F.; Nomura, C. S.; Naozuka, J.; Sci. Rep. 2019 9, 1.

13. Ekanayake, L. J.; Vial, E.; Schatz, B.; McGee, R.; Thavarajah, P.; Field Crops Res. 2015, 177, 9.

14. Cornelis, R.; Caruso, J. A.; Crews, H.; Heumann, K.; Handbook of elemental speciation II, $5^{\text {th }}$ ed., John Wiley, 2005.

15. Cozzolino, S. M. F.; Biodisponibilidade de nutrientes, Manole: São Paulo, 2007

16. Peixoto, R. R.; Mazon, E. A.; Cadore, S.; J. Braz. Chem. Soc. 2013, 24, 884.

17. Ekmekcioglu, C.; Food Chem. 2002, 76, 225.

18. Sgarbieri, V. C.; Pacheco, M. T. B.; Braz. J. Food Technol. 1999, 21, 7.

19. https://apps.webofknowledge.com/WOS_GeneralSearch_input. do? product $=$ WOS \&search_mode $=$ GeneralSearch $\&$ SID $=8$ EDblAQ9Eh KaMUh5uA5\&preferencesSaved=, acessada em Julho de 2020.

20. da Silva, E. N.; Cidade, M.; Heerdt, G.; Ribessi, R. L.; Morgon, N. H.; Cadore, S.; J. Braz. Chem. Soc. 2018, 29, 371.

21. Ríos, J. J.; Rosales, M. A.; Blasco, B.; Cervilla, L. M.; Romero, L.; Ruiz, J. M.; Sci. Hortic. 2008, 116, 248.

22. Kleiber, T.; Ecol. Chem. Eng. 2014, 21, 529.

23. Padash, A.; Shahabivand, S.; Behtash, F.; Aghaee, A.; Sci. Hortic. 2016, $213,367$.

24. Lu, Q.; He, Z. L.; Graetz, D. A.; Stoffella, P. J.; Yang, X.; Environ. Sci. Pollut. Res. 2011, 18, 978.

25. Businelli, D.; D’Amato, R.; Onofri, A.; Tedeschini, E.; Tei, F.; Sci. Hortic. 2015, 197, 697

26. do Nascimento da Silva, E.; Aureli, F.; D’Amato, M.; Raggi, A.; Cadore, S.; Cubadda, F.; J. Agric. Food Chem. 2017, 65, 3031.

27. Smoleń, S.; Kowalska, I.; Kováčik, P.; Halka, M.; Sady, W.; Front. Plant Sci. 2019, 10 .

28. Hawrylak-Nowak, B.; Plant Growth Regul. 2013, 70, 149.

29. Ip, C.; Birringer, M.; Block, E.; Kotrebai, M.; Tyson, J. F. Uden, P. C.; Lisk, D. J.; J. Agric. Food Chem. 2000, 48, 2062. 
30. Larsen, E. H.; Lobinski, R.; Burger-Meÿer, K.; Hansen, M.; Ruzik, R. Mazurowska, L.; Kik, C.; Anal. Bioanal. Chem. 2006, 385, 1098.

31. Polyakov, A.; Alekseeva, T.; Soldatenko, A. In IOP Conference Series: Earth and Environmental Science, 2019

32. Sharma, S.; Bansal, A.; Dhillon, S. K.; Dhillon, K. S.; Plant Soil 2010 329, 339

33. Wei, Y.; Shohag, M. J. I.; Ying, F.; Yang, X.; Wu, C.; Wang, Y.; Food Chem. 2013, 138, 1952.

34. Turakainen, M.; Hartikainen, H.; Sarjala, T.; Seppänen, M. M.; J. Agric. Food Sci. 2008, 17, 278.

35. Przybysz, A.; Wrochna, M.; Małecka-Przybysz, M.; Gawrońska, H.; Gawroński, S. W. Sci. Hortic. 2016, 203, 110.

36. Przybysz, A.; Wrochna, M.; Małecka-Przybysz, M.; Gawrońska, H.; Gawroński, S. W.; J. Sci. Food Agric. 2016, 96, 3469.

37. Zhong, N.; Zhong, L.; Hao, L.; Luan, C.; Li, X.; Anal. Lett. 2015, 48, 180.

38. Tian, M.; Xu, X.; Liu, Y.; Xie, L.; Pan, S.; Food Chem. 2016, 190, 374.

39. Arscott, S.; Goldman, I. HortScience 2012, 47, 497.

40. Piekarska, A.; Kołodziejski, D.; Pilipczuk, T.; Bodnar, M.; Konieczka, P.; Kusznierewicz, B.; Namieśnik, J.; Int. J. Food Sci. Nutr. 2014, 65 , 692.

41. Ávila, F. W.; Yang, Y.; Faquin, V.; Ramos, S. J.; Guilherme, L. R. G.; Thannhauser, T. W.; Li, L.; Food Chem. 2014, 165, 578.

42. Lingyun, Y.; Jian, W.; Chenggang, W.; Shan, L.; Shidong, Z.; J. Food Nutr. Res. 2016, 4, 100.

43. Bódi, É.; Fekete, I.; Andrási, D.; Kovács, B.; Eur. Chem. Bull. 2012, 2 , 46.

44. Oliveira, A. P.; Nomura, C. S.; Silva, S. G. D.; Naozuka, J.; J. Anal. Pharm. Res. 2018, 7, 104.

45. de Oliveira, A. P.; Nomura, C. S.; Naozuka, J.; Microchem. J. 2017, 134, 19.

46. Blicharska, E., Komsta, Ł., Kocjan, R., Gumieniczek, A., Kloc, A., \& Kaźmierczak, J.; Acta Chromatogr. 2014, 26, 739.

47. Tie, M.; Gao, Y.; Xue, Y.; Zhang, A.; Yao, Y.; Sun, J.; Xue, S.; Anal. Methods. 2016, 8, 3102.

48. Bai, H. S.; Kim, H. S.; Bai, S. C.; Kim, D. J. J. Food Sci. Nutr. 2009, 14, 142.

49. Trolove, S. N.; Tan, Y.; Morrison, S. C.; Feng, L.; Eason, J.; LWT-Food Sci Technol, 2018, 95, 187.

50. Zielińska-Dawidziak, M.; Siger, A.; Eur. Food Res. Technol. 2012, 234 , 1005.

51. Barak, P.; Goldman, I. L.; J. Agric. Food Chem. 1997, 45, 1290.,

52. Jordão, C. P.; Fialho, L. L.; Cecon, P. R.; Matos, A. T.; Neves, J. C. L.; Mendonça, E. S.; Fontes, R. L. F.; Water Air Soil Pollut. 2006, 172, 21.

53. Kápolna, E.; Hillestrøm, P. R.; Laursen, K. H.; Husted, S.; Larsen, E. H.; Food Chem. 2009, 115, 1357.

54. Maneetong, S.; Chookhampaeng, S.; Chantiratikul, A.; Chinrasri, O.; Thosaikham, W.; Sittipout, R.; Chantiratikul, P.; Microchem. J. 2013 , 108, 87.

55. Pandey, N.; Gupta, B.; Pathak, G. C.; Sci. Hortic. 2013, 164, 474.

56. Smrkolj, P.; Osvald, M.; Osvald, J.; Stibilj, V.; Eur. Food Res. Technol. 2007, 225, 233.

57. Yu, Y.; Luo, L.; Yang, K.; Zhang, S.; Pedobiologia 2011, 54, 267.

58. Zou, T.; Xu, N.; Hu, G.; Pang, J.; Xu, H.; J. Sci. Food Agric. 2014, 94 , 3053.

59. Chan, Q.; Caruso, J. A.; Anal. Bioanal. Chem. 2012, 403, 1311.

60. Seppänen, M. M.; Kontturi, J.; Heras, I. L.; Madrid, Y.; Cámara, C.; Hartikainen, H.; Plant Soil 2010, 337, 273.

61. Bañuelos, G. S.; Stushnoff, C.; Walse, S. S.; Zuber, T.; Yang, S. I.; Pickering, I. J.; Freeman, J. L.; Food Chem. 2012, 135, 9.

62. Pezzarossa, B.; Rosellini, I.; Borghesi, E.; Tonutti, P.; Malorgio, F.; Sci. Hortic. 2014, 165, 106.

63. Werner, A. R.; Beelman, R. B.; Int. J. Med. Mushrooms 2002, 4, 88.
64. Huerta, V. D.; Sánchez, M. L. F.; Sanz-Medel, A. Anal. Bioanal. Chem. 2006, 384, 902

65. Rzymski, P.; Mleczek, M.; Niedzielski, P.; Siwulski, M.; Gąsecka, M.; J. Sci. Food Agric. 2017, 97, 923.

66. Solovyev, N.; Prakash, N. T.; Bhatia, P.; Prakash, R.; Drobyshev, E.; Michalke, B.; J. Trace Elem. Med. Biol. 2018, 50, 362.

67. Maseko, T.; Callahan, D. L.; Dunshea, F. R.; Doronila, A.; Kolev, S. D.; Ng, K.; Food Chem. 2013, 141, 3681.

68. Prange, A.; Sari, M.; von Ameln, S.; Hajdu, C.; Hambitzer, R.; Ellinger, S.; Hormes, J.; J. Trace Elem. Med. Biol. 2019, 1, 164.

69. Rabinovich, M.; Figlas, D.; Delmastro, S.; Curvetto, N.; J. Med. Food 2007, 10, 175 .

70. Rathore, H.; Sharma, A.; Prasad, S.; Sharma, S.; J. Biosci. Bioeng. 2018 $126,482$.

71. Hu, T.; Liang, Y.; Zhao, G.; Wu, W.; Li, H.; Guo, Y.; Biol. Trace Elem. Res. 2019, 187, 553.

72. Wang, J.; Wang, B.; Zhang, D.; Wu, Y.; PeerJ 2016, 4, e1993.

73. Zhao, L.; Zhao, G.; Zhao, Z.; Chen, P.; Tong, J.; Hu, X. J. Agri. Food Chem. 2004, 52, 3954.

74. Rzymski, P.; Mleczek, M.; Niedzielski, P.; Siwulski, M.; Gąsecka, M.; J. Food Sci. 2016, 81, C587.

75. Zhao, L.; Zhao, G.; Du, M,; Zhao, Z.; Xiao, L.; Hu, X.; Eur. Food Res. Technol. 2008, 226, 499.

76. Beelman, R. B.; Royse, D. J.; Int. J. Med. Mushrooms 2006, 8, 1.

77. Figlas, D.; Oddera, M.; Curvetto, N.; J. Med. Food 2010, 13, 469.

78. Yoshida, M.; Sugihara, S.; Inoue, Y.; Chihara, Y.; Kondô, M.; Miyamoto, S.; Sukcharoen, B.; J. Nutr. Sci. Vitaminol. 2005, 51, 194.

79. Ogidi, C. O.; Akindulureni, E. D.; Agbetola, O. Y.; Akinyele, B. J.; Waste Biomass Valorization 2019, 1.

80. Ogra, Y.; Ishiwata, K.; Encinar, J. R.; Łobiński, R.; Suzuki, K. T.; Anal. Bioanal. Chem. 2004, 379, 861

81. Zhou, F.; Yang, W.; Wang, M.; Miao, Y.; Cui, Z.; Li, Z.; Liang, D.; Food Chem. 2018, 265, 182.

82. Ogidi, C. O.; Nunes, M. D.; da Silva, M. D. C. S.; Oyetayo, V. O., Akinyele, B. J.; Kasuya, M. C. M. Current Res. Nutr. Food Sci. J. 2017, 5,137

83. Ogidi, O. C.; Nunes, M. D.; Oyetayo, V. O.; Akinyele, B. J.; Kasuya, M. C. M.; J. Food Res. 2016, 5, 13.

84. Oliveira, A. P.; Naozuka, J.; Microchem. J. 2019, 145, 1143

85. Niedzielski, P.; Mleczek, M.; Siwulski, M.; Rzymski, P.; Gąsecka, M.; Kozak, L. Eur. Food Res. Technol. 2015, 241, 419.

86. Gąsecka, M.; Mleczek, M.; Siwulski, M.; Niedzielski, P.; Eur. Food Res. Technol. 2016, 242, 723.

87. Bhatia, P.; Aureli, F.; D'Amato, M.; Prakash, R.; Cameotra, S. S.; Nagaraja, T. P.; Cubadda, F.; Food Chem. 2013, 140, 225.

88. Vieira, P. A. F.; Gontijo, D. C.; Vieira, B. C.; Fontes, E. A.; de Assunção, L. S.; Leite, J. P. V.; Kasuya, M. C. M.; LWT--Food Sci. Technol. 2013, $54,421$.

89. da Silva, M. D. C. S.; da Luz, J. M. R.; Paiva, A. P. S.; Mendes, D. R.; Carvalho, A. A.; Naozuka, J.; Kasuya, M. C. M.; J. Agric. Sci. 2019, 11.

90. da Silva, M. C.; Naozuka, J.; Oliveira, P. V.; Vanetti, M. C.; Bazzolli, D. M.; Costa, N. M.; Kasuya, M. C.; Metallomics 2010, 2, 162.

91. Serafin Muñoz, A. H.; Kubachka, K.; Wrobel, K.; Gutierrez Corona, J. F.; Yathavakilla, S. K.; Caruso, J. A.; Wrobel, K.; J. Agri. Food Chem. 2006, 54,3440

92. Savić, M. D.; Petrović, J. P.; Klaus, A. S.; Nikšić, M. P.; Rajković, M. B.; Filipović, N. R., Antić-Mladenović, S. B.; Zbornik Matice srpske za prirodne nauke 2009, 116, 209.

93. Milovanović, I.; Brčeski, I.; Stajić, M.; Korać, A.; Vukojević, J.; Knežević, A.; Sci. World J. 2014, 2014, 1.

94. Assunção, L. S. D.; Silva, M. C. S.; Fernandez, M. G.; García-Barrera, T.; Goméz-Ariza, J. L.; Bautista, J.; Kasuya, M. C. M.; J. Biotech. Lett. 2014, 5,79 
95. Yan, H.; Chang, H.; Biol. Trace Elem. Res. 2012, 150, 236.

96. Carrasco-Gonzalez, J. A.; Serna-Saldívar, S. O.; Gutierrez-Uribe, J. A.; J. Agric. Food Chem. 2017, 65, 4074.

97. Zhou, F.; Dinh, Q. T.; Yang, W.; Wang, M.; Xue, M.; Bañuelos, G. S.; Liang, D.; Ecotoxicol. Environ Saf. 2019, 185, 109675.

98. Bhatia, P.; Prakash, R.; Prakash, N. T.; International Journal of Recycling of Organic Waste in Agriculture 2014, 3, 127.

99. Brown, T. A.; Shrift, A.; Biol. Rev. 1982, 57, 59.

100. https://www.harvestplus.org/, acessada em Julho 2020.

101. Corbo, J. Z. F.; Dissertação de Mestrado, Instituto Agronômico de Campinas, Brasil, 2014.

102. Bellenda, B.; LEISA revista de agroecologia 2005 21, 29.

103. Kumar, V.; Singh, J.; Chopra, A. K.; Int. J. Phytorem. 2018, $20,507$.

104. Das, A.; Kamal, S.; Shakil, N. A.; Sherameti, I.; Oelmüller, R.; Dua, M.; Tutuja, M.; Johri, A. K.; Varma, A.; Plant Signal Behav. 2012, 7, 103.

105. Yadav, V.; Kumar, M.; Deep, D. K.; Kumar, H.; Sharma, R.; Tripathi, T.; Tuteja, N.; Saxena, A. K.; Johri, A. K.; J. Biol. Chem. 2010, 285, 26532.

106. Rahman, K.; Lowe, G. M.; J. Nutr. 2006, 136, 736S.

107. Finley, J. W.; J. Med. Food 2003, 6, 19.

108. Tsuneyoshi, T.; Yoshida, J.; Sasaoka, T.; The Journal of Nutrition 2006, $136,870 \mathrm{~S}$.

109. Kabata-Pendias, A.; Pendias, H.; Trace elements in soils and plants, $3^{\text {rd }}$ ed, CRC Pres: Florida, 2001.

110. Römheld, V.; Marschner, H.; Plant Physiol. 1986, 80, 175-180.

111. Sors, T. G.; Ellis, D. R.; Salt, D. E.; Photosynth. Res. 2005, 86, 373.

112. de la Luz Mora; M., Pinilla, L.; Rosas, A.; Cartes, P.; Plant Soil 2008, $303,139$.

113. Nakamaru, Y. M.; Sekine, K.; Soil Sci. Plant Nutr. 2008, 54, 332.

114. Terry, N.; Zayed, A. M.; De Souza, M. P.; Tarun, A. S.; Annu. Rev. Plant Biol. 2000, 51, 401.

115. Pilon-Smits, E. A.; Quinn, C. F.; Cell biology of metals and nutrients, $1^{\text {st }}$ ed, Springer: Berlin, 2010.

116. Ereno, D.; Pesquisa FAPESP 2004, 138.

117. Mattila, P.; Könkö, K.; Eurola, M.; Pihlava, J. M.; Astola, J.; Vahteristo, L.; Piironen, V.; J. Agri. Food Chem. 2001, 49, 2343.

118. Mallikarjuna, S. E.; Ranjini, A.; Haware, D. J.; Vijayalakshmi, M. R.; Shashirekha, M. N.; Rajarathnam, S.; J. Chem. 2012, 2013.

119. Sarangi, I.; Ghosh, D.; Bhutia, S. K.; Mallick, S. K.; Maiti, T. K.; Int. Immunopharmacol. 2006, 6, 1287.

120. Nieuwenhuijzen, B. V.; Oei, P.; O cultivo de cogumelos em pequena escala: pleuroto, shiitake e orelha-de-pau, Agromisa/CTA, 2006.

121. Tesfaw, A.; Tadesse, A.; Kiros, G.; J. Appl. Biol. Biotechnol. 2015, 3, 15.

122. Pathmashini, L.; Arulnandhy, V.; Wijeratnam, R. S.; Cey. J. Sci. (Bio. Sci.) 2009, 37, 177.

123. Marino, R. H.; de Abreu, L. D.; Revista Brasileira de Ciências Agrárias 2, 17709, 4, 11.

124. Damodaran, D.; Balakrishnan, R. M.; Shetty, V. K.; BioMed Res. Int. 2013, 2013.

125. Li, X.; Wang, Y.; Pan, Y.; Yu, H.; Zhang, X.; Shen, Y.; Zhang, S.; J. Hazard. Mater. 2017, 330, 1.

126. Huerta, V. D.; Sánchez, M. L. F.; Sanz-Medel, A.; Anal. Chim. Acta 2005, 538, 99 .

127. Falandysz, J.; J. Environ. Sci. Health, C 2008, 26, 256.

128. de Assunção, L. S.; da Luz, J. M. R.; da Silva, M. D. C. S.; Vieira, P. A. F.; Bazzolli, D. M. S.; Vanetti, M. C. D.; Kasuya, M. C. M.; Food Chem. 2012, 134, 1123.

129. Mleczek, M.; Magdziak, Z.; Gąsecka, M.; Niedzielski, P.; Kalač, P.; Siwulski, M.; Sobieralski, K.; Environ. Sci. Pollut. Res. 2016, 23, 20609.

130. Zhang, D.; Gao, T.; Ma, P.; Luo, Y.; Su, P.; Wuhan Univ. J. Nat. Sci. 2008, 13, 267.

131. Isildak, O.; Turkekul, I.; Elmastas, M.; Aboul-Enein, H. Y.; Anal. Lett. 2007, 40, 1099.

132. Ita, B. N.; Essien, J. P.; Ebong, G. A.; J. Agric. Soc. Sci. 2006, $2,84$.
133. Demirbaş, A.; Food Chem. 2001, 74, 293.

134. Garcia, M. A.; Alonso, J.; Fernández, M. I.; Melgar, M. J.; Arch. Environ. Contam. Toxicol. 1998, 34, 330.

135. Arıca, M. Y.; Arpa, C.; Kaya, B.; Bektaş, S.; Denizli, A.; Genç, Ö.; Bioresour. Technol. 2003, 89, 145.

136. Guyton, A. C.; Hall, J. E.; Guyton, A. C.; Tratado de fisiologia médica 2006. Elsevier: Brasil.

137. https://www.fda.gov/Food/GuidanceRegulation/GuidanceDocuments RegulatoryInformation/Labeling Nutrition/ucm064928.htm, acessada em Julho 2020.

138. Cakmak, I.; Pfeiffer, W. H.; McClafferty, B.; Cereal Chem. 2010, 87, 10.

139. https://tabnut.dis.epm.br/alimento/16001/feijao-azuki-semente-maduracru, acessada em Julho 2020

140. Oliveira, A. P.; Naozuka, J.; J. Braz. Chem. Soc. 2015, 26, 2144.

141. Ramírez-Cárdenas, L.; Costa, N. M. B.; Reis, F. P.; Nutr. Res. 2005, 25, 79.

142. dos Santos Obelar, M.; Revista Paulista de Pediatria 2008, 26, 4.

143. Moura, N. C. D.; Canniatti-Brazaca, S. G.; Food Sci. Technol. 2006, 26, 270.

144. Karp, G.; Biologia celular e molecular: conceitos e experimentos, $3^{\text {rd }}$ ed., Manole: São Paulo, 2005.

145. Powell, J. J.; Jugdaohsingh, R.; Thompson, R. P. H.; Proceedings of the Nutrition Society 1999, 58, 147.

146. Kaplan, J.; Cell 2002, 111, 603.

147. Waters, D. J.; Shen, S.; Kengeri, S.; Xu, H.; Schlittler, D.; Chiang, E.; Glickman, L. T.; Cancer Epidemiol. Biomarkers Prev. 2006, 47, 424.

148. Pyrzynska, K.; Food Chem. 2009, 114, 1183.

149. Ip, C.; Ganther, H. E.; Carcinogenesis 1992, 13, 1167.

150. Correia, P. R. M.; Dissertação de Mestrado, Universidade de São Paulo, Brasil, 2001.

151. Vieira, R. F. Produção de brotos comestíveis: feijão moyashi, alfafa, trevo, rabanete e brócolis, CPT: EPAMIG, 2001.

152. Yousif, A. M.; Deeth, H. C.; Food Chem. 2003, 81, 169.

153. Sato, S.; Yamate, J.: Hori, Y.; Hatai, A.; Nozawa, M.; Sagai, M.; J. Nutr. Biochem. 2005, 16, 547.

154. Li, L.; Liu, B.; Zheng, X.; J. Med. Plants Res. 2011, 5, 5894.

155. Lourdes, N. T. P.; Dissertação de Mestrado, Universidade Estadual do Oeste do Paraná, 2007.

156. Mbithi, S.; Van Camp, J.; Rodriguez, R.; Huyghebaert, A. Eur. Food Res. Technol. 2001, 212, 188.

157. Sangronis, E.; Machado, C. J.; LWT-Food Sci. Technol. 2007, 40, 116.

158. Ribeiro, M. L. L.; Ida, E. I.; Oliveira, M. C. N. D.; Pesq. agropec. bras. 1999, 34, 31 .

159. Black, R. E.; Allen, L. H.; Bhutta, Z. A.; Caulfield, L. E.; De Onis, M.; Ezzati, M.; Lancet 2008, 371, 243.

160. Shanker, A.; Venkateswarlu, B.; Abiotic Stress Response in Plants: Physiological, Biochemical and Genetic Perspectives, InTech: Croácia, 2011.

161. Kader, J. C.; Delseny, M.; Advances in botanical research, $1^{\text {st }}$ ed., Academic Press: Londres, 2007.

162. Kobayashi, T.; Nishizawa, N. K.; Annu. Rev. Plant Biol. 2012, 63, 131.

163. Bothwell, T. H.; MacPhail, A. P.; International journal for vitamin and nutrition research 2004, 74, 421

164. Sun, S. S.; Leung, F. W.; Tomic, J. C.; J. Agri. Food Chem. 1987, 35, 232.

165. Cartes, P.; Gianfreda, L.; Mora, M. L.; Plant and Soil 2005, 276, 359.

166. Han, D.; Li, X.; Xiong, S.; Tu, S.; Chen, Z.; Li, J.; Xie, Z.; Environ. Exp. Bot. 2013, 95, 6.

167. Zayed, A.; Lytle, C. M.; Terry, N.; Planta 1998, 206, 284.

168. Pilon-Smits, E.; Quinn, C. In Cell biology of metal and nutrients; Hell, R., Mendel, R.-R., eds.; Springer: Berlin, 2010.

169. Li, H. F.; McGrath, S. P.; Zhao, F. J.; New Phytologist 2008, 178, 92.

170. Chen, S.; Zhu, S.; Lu, D.; Food Chem. 2015, 169, 156. 
171. Rayman, M. P.; Br. J. Nutr. 2008, 100, 254.

172. Sudha, G.; Janardhanan, A.; Moorthy, A.; Chinnasamy, M.; Gunasekaran, S.; Thimmaraju, A.; Gopalan, J.; Food Sci. Biotechnol. 2016, 25, 371 .

173. Nunes, R. G. F. L.; Tese de Doutorado, Universidade Federal de Viçosa, Brasil, 2005.

174. Burk, R. F.; Hill, K. E.; Motley, A. K.; The Journal of nutrition 2003 $133,1517 \mathrm{~S}$.
175. Chunhieng, T.; Pétritis, K.; Elfakir, C.; Brochier, J.; Goli, T.; Montet, D.; J. Agri. Food Chem. 2004, 52, 4318.

176. Cunha Antunes, D.; Lima, I. M.; Silva, W. M. D. S. C.; Revista Brasileira de Cancerologia 2010, 56, 367.

177. Fernandes, A. P.; Gandin, V.; Biochim. Biophys. Acta 2015, 1850, 1642. 178. Vitali, D.; Dragojević, I. V.; Šebečić, B.; Food Chem. 2008, 110, 62.

179. Naozuka, J.; Marana, S. R.; Oliveira, P. V.; J. Food Compos. Anal. 2010 , 23,85 . 